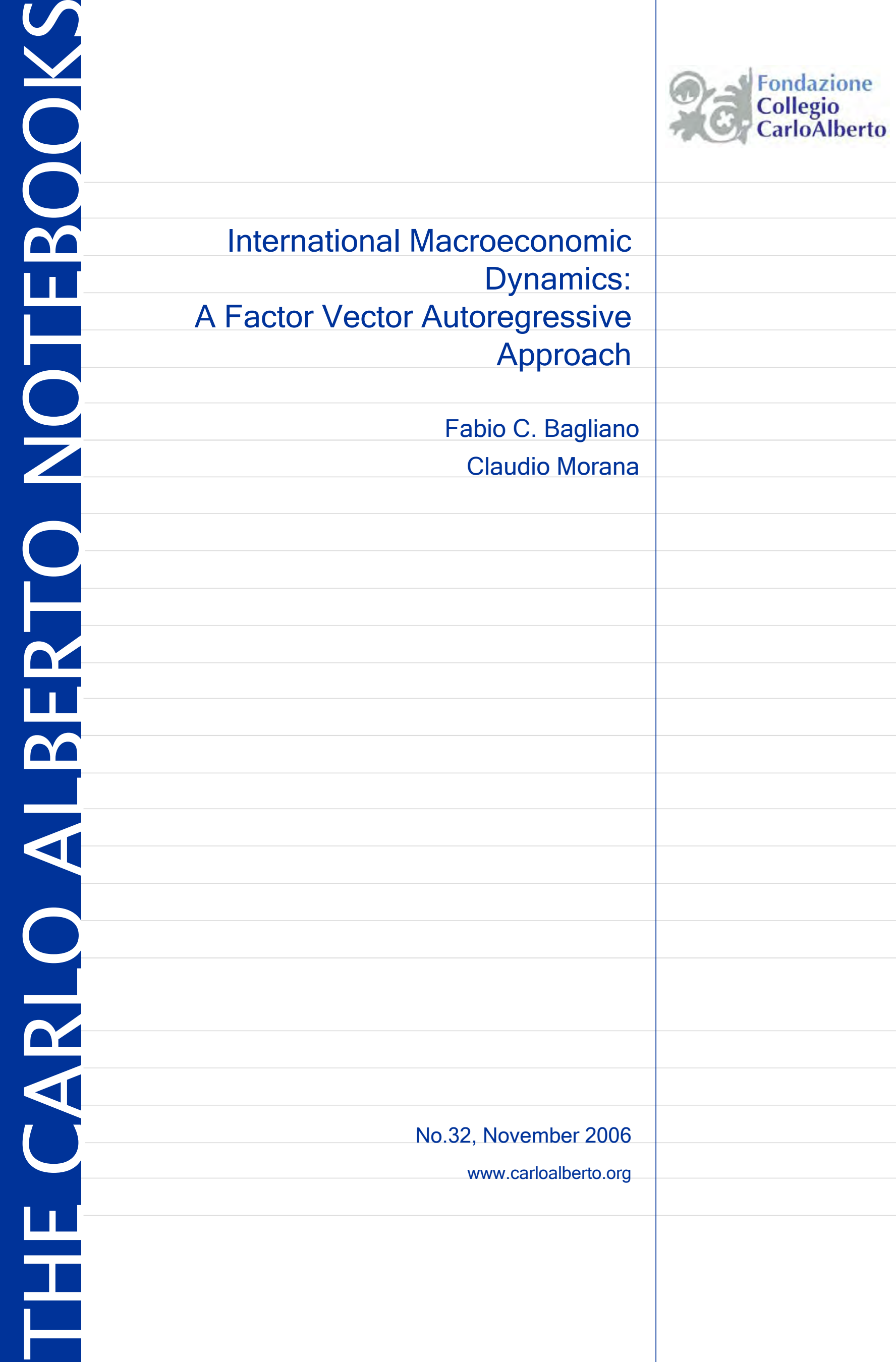




\title{
International Macroeconomic Dynamics: A Factor Vector Autoregressive Approach *
}

\author{
Fabio C. Bagliano \\ Dipartimento di Scienze Economiche e Finanziarie, Università di Torino (Italy) \\ and Collegio Carlo Alberto, Moncalieri (Italy) \\ Claudio Morana \\ Dipartimento di Scienze Economiche e Metodi Quantitativi, \\ Università del Piemonte Orientale, Novara (Italy), \\ International Centre for Economic Research (ICER, Torino) \\ and Department of Economics, Michigan Sate University ${ }^{\dagger}$
}

October 2006

*(C) 2006 by F.C. Bagliano and C. Morana. Any opinions expressed here are those of the authors and not those of the Fondazione Collegio Carlo Alberto.

${ }^{\dagger}$ Address for correspondence: Claudio Morana, Università del Piemonte Orientale, Facoltà di Economia, Dipartimento di Scienze Economiche e Metodi Quantitativi, Via Perrone 18, 28100, Novara, Italy. E-mail: claudio.morana@eco.unipmn.it 


\begin{abstract}
In this paper international comovements among a set of key real and nominal macroeconomic variables for the G-7 countries have been investigated for the 19802005 period, using a Factor Vector Autoregressive approach. We present evidence that comovements in macroeconomic variables do not concern only real activity, but are an important feature also of stock market returns, inflation rates, interest rates and, to a smaller extent, monetary aggregates. Both common sources of shocks and similar transmission mechanisms explain international comovements, with the only exception of Japan, where the idiosyncratic features seem to dominate. Finally, concerning the origin of global shocks, evidence of both global supply-side and demand-side disturbances is found.
\end{abstract}

JEL classification n.: C22, E31, E32.

Keywords: G7, international business cycle, factor vector autoregressive models, common factors 


\section{Introduction}

Several papers have recently investigated the existence and importance of common patterns in the international dynamics of macroeconomic variables, with a focus on the changes over time of business cycle synchronization among the major economies due to common global disturbances.

From a business cycle perspective, the analysis has mainly concerned the international comovements of GDP (and, in some cases, also consumption and investment) growth rates, documenting a number of empirical regularities. ${ }^{1}$ Doyle and Faust (2005), Kose, Otrok and Whiteman (2005) and Stock and Watson (2003, 2005b), among others, find no overall tendency towards closer synchronization of cyclical fluctuations among G7 economies over the 1960-2002 period, despite the substantial increase in international trade flows and financial markets integration. This feature is nevertheless consistent with an increased importance of common shocks as a driving force of international output fluctuations since the early 1980s: the smaller magnitude of the shocks in the more recent period relative to the previous two decades can explain a broadly constant pattern of correlations among GDP growth rates across countries. However, Helbling and Bayoumi (2003), Monfort, Renne, Rufle, and Vitale (2003), and Stock and Watson (2005b) provide some evidence of increased synchronization among the largest economies of the Euro-zone and among the English-speaking countries (the US, the UK, and Canada), whereas Japanese cycles bear very little correlation with the other G7 economies. ${ }^{2}$

A robust finding from this literature is that the commonalities in business cycle fluctuations can be related to a small number of global factors. For instance, Kose, Otrok and Whiteman (2005) report that a single world factor, extracted from the growth rates of GDP, consumption and investment of the G7 countries, is able to explain around $25 \%$ of the total variance of G7 output growth over the 1960-2003 period. Focusing on output growth only, Stock and Watson (2005b) find that two common international shocks account for $47 \%$ of the US GDP growth variance at a two-year horizon (30\% in the case of the UK) over the more recent 1984-2002 period. Finally, Canova, Ciccarelli and Ortega (2004) confirm the evidence of a world business cycle, since a significant portion (around 30\%) of the fluctuations in sales, industrial production, output and employment in the G7 countries from 1979 to 2002

\footnotetext{
${ }^{1}$ See Stock and Watson (2005b), and the references therein, for an updated summary of recent evidence on the evolution of international business cycle dynamics.

${ }^{2}$ These findings are not entirely undisputed. For example, Kose, Otrok and Whiteman (2003) and Canova, Ciccarelli and Ortega (2004) argue that, although there is evidence of a world business cycle, no European cycle can be detected.
} 
can be attributed to a common indicator. Finally, various interpretations of the economic nature of the common disturbances have been put forward. Stock and Watson (2005b) relate the global output growth shocks in the 1960s and 1970s to US monetary policy, the oil price and prices of industrial materials, though in the 1980s and 1990s only the link with the latter variable can still be found. Canova and de Nicolò (2003) identify the main source of common output (and inflation) fluctuations in the G7 countries with demand disturbances, though the international synchronization of business cycles is attributed more to similarities in the transmission mechanism than to common sources of shocks.

While most of the evidence on international comovements has been provided for the growth rates of output and its main components, some results are also available for other macroeconomic and financial variables. For instance, Morana and Beltratti (2006) show that, over the 1973-2004 period, a global stock market factor explains about $60 \%$ of the total return variance across four major international stock markets (the US, the UK, Germany and Japan). Yet, due to the stagnation suffered by Japan during the 1990s, the Japanese stock market in the last fifteen years has shown a more idiosyncratic behavior: in fact, the global factor accounts for 85\% of the 1990-2004 stock return variance for Germany and $76 \%$ for the US and the UK, while for Japan the figure is $36 \%$ only. Moreover, Ehrmann, Fratzscher and Rigobon (2005) find that since 1990, overall movements in the US financial markets explain about $25 \%$ of fluctuations in the Euro-area financial markets, while the latter can account for no more than $8 \%$ of fluctuations in the US markets. Strong interactions can also be found across asset classes, where changes in the US (Euro-area) short term interest rate affect both the Euro-area (US) stock and bond markets. Finally, Ciccarelli and Mojon (2005) show that inflation in industrialized economies is mainly determined by common driving forces. A single global factor can explain not only the trend component of inflation but also fluctuations at business cycle frequencies, accounting for about $70 \%$ of the overall variance of the inflation rates in 22 OECD countries.

Another strand of empirical literature models the interactions among broader sets of macroeconomic variables, with the main focus on the spillovers of shocks across regions (particularly the US and the Euro-zone). This is the case of the global error-correction VAR models of Pesaran, Schuermann and Weiner (2004) and Dees, di Mauro, Pesaran and Smith (2005), where regionspecific models are individually estimated with (appropriately constructed) foreign variables included to capture international relations. The individual models are then consistently linked and the dynamic responses of all variables across regions to, for example, shocks to US equity prices and to German output, are evaluated. Also the effects of observed global factors 
(such as oil prices) are accommodated within this approach. ${ }^{3}$

Overall, the existing literature analyzes international macroeconomic dynamics mainly by considering a limited set of real quantities (output, consumption, investment), in some cases for a large number of countries. When the analysis is extended to a broader range of variables, the focus is more on the spillovers of shocks than on the common driving forces of fluctuations. In this paper we study comovements among the US, the UK, Japan, Canada, and the countries of the Euro-area, using a larger data set than previously employed in the literature, including both real and nominal variables. We adopt a new econometric approach based on the Factor-Augmented Vector Autoregression $(F-V A R)$ model described in Stock and Watson (2005b). We modify the Stock-Watson methodology in order to allow for a more straightforward economic interpretation of the unobservable global factors; moreover, the relative importance of domestic and foreign idiosyncratic (country-specific) disturbances in determining macroeconomic fluctuations can be gauged by adopting our identification strategy.

To preview, the key findings of the paper are the following. First, the comovements in macroeconomic variables do not concern real activity only, but are an important feature also of stock market returns, inflation rates, interest rates and, to a smaller extent, monetary aggregates. Second, both common sources of shocks and similar transmission mechanisms explain international comovements. Finally, concerning the origin of global shocks, evidence of both global supply-side and demand-side disturbances is found.

The rest of the paper is organized as follows. In the next section the econometric methodology is presented, while in section 3 the data and their persistence properties are discussed. The estimation of the common factors driving international macroeconomic dynamics is carried out in section 4 . Then, in section 5 the relative contribution of global and idiosyncratic factors to the fluctuations of macroeconomic variables in each region is assessed; differences and similarities across regions in the transmission of the common factor shocks are also evaluated. Finally, the main conclusions are drawn in section 6 .

\section{Econometric methodology}

To investigate the comovements of a set of key macroeconomic variables (including the growth rate of GDP, the inflation rate, short- and long-term

\footnotetext{
${ }^{3}$ With a narrower scope, Sousa and Zaghini (2004) have recently studied the spillover effects of foreign liquidity (measured as the aggregate excess broad money for the US, the UK, Japan and Canada) on the Euro-area economy over the 1980-2001 period.
} 
interest rates, the rate of nominal money growth, the rate of change in real stock prices, the real exchange rate, and the real oil price) for five regions (the United States, Japan, the Euro-12 area, the United Kingdom, and Canada) and their dynamic responses to structural disturbances, we adopt the factor vector autoregressive framework derived from a dynamic factor model, as in Stock and Watson (2005a). The basic assumption of the dynamic factor model is that the observed comovement of a (potentially very large) set of time series is attributable to a relatively small number of unobserved common dynamic factors. Such factors are driven by common structural economic disturbances, that need to be identified in order to address policy-relevant issues. The dynamics of the observed variables not due to the common factors is attributed to idiosyncratic shocks, uncorrelated with the common disturbances.

This section describes the factor vector autoregressive model in more detail and provides some discussion of the adopted estimation methodology.

\subsection{The Factor Vector Autoregressive model}

We model the joint dynamics of $r$ macroeconomic variables for each of the $m$ countries (or regions) of interest by means of the following dynamic factor model (Stock and Watson, 2005a) $:^{4}$

$$
\begin{aligned}
\mathbf{X}_{t} & =\boldsymbol{\Lambda} \mathbf{F}_{t}+\mathbf{D}(L) \mathbf{X}_{t-1}+\mathbf{v}_{t} \\
\mathbf{F}_{t} & =\boldsymbol{\Phi}(L) \mathbf{F}_{t-1}+\boldsymbol{\eta}_{t},
\end{aligned}
$$

In (1) $\mathbf{X}_{t}$ is the $n$-variate vector of the stationary variables of interest, with $n=m \times r, \mathbf{F}_{t}$ is an $r$-variate vector of unobserved common factors, $\boldsymbol{\Lambda}$ is the corresponding $n \times r$ matrix of loading coefficients (capturing the weight of each factor for each variable in $\mathbf{X}), \mathbf{D}(L)$ is a $n \times n$ matrix lag polynomial of appropriate order $p$, and $\mathbf{v}_{t}$ is the $n$-variate vector of the reduced-form idiosyncratic (iid) disturbances. Moroever, $\boldsymbol{\Phi}(L)$ is a $r \times r$ matrix lag polynomial of order $p$, and $\boldsymbol{\eta}_{t}$ is a vector of global shocks driving the common factors with $E\left[\eta_{j t} v_{i s}\right]=0$ for all $i, j, t, s .{ }^{5}$ The latter shocks have the nature of reduced-form innovations and are linear combinations of the underlying structural global disturbances: an identification scheme must then be used in

\footnotetext{
${ }^{4}$ For ease of exposition, any deterministic element (a constant, and linear and possibly non-linear time trends) is omitted.

${ }^{5}$ The model in (1) and (2) corresponds to the static form representation of the dynamic factor model of Stock and Watson (2005a), since in our empirical application the number of static and dynamic factor coincide. In general, $\mathbf{F}_{t}$ may contain lags of the original dynamic factors.
} 
order to extract the structural shocks driving factor dynamics and to proceed to their economic interpretation.

By substituting (2) into (1), the dynamic factor model can be written in vector autoregressive $(F-V A R)$ form as

$$
\left(\begin{array}{c}
\mathbf{F}_{t} \\
\mathbf{X}_{t}
\end{array}\right)=\left(\begin{array}{cc}
\boldsymbol{\Phi}(L) & \mathbf{0} \\
\Lambda \boldsymbol{\Phi}(L) & \mathbf{D}(L)
\end{array}\right)\left(\begin{array}{c}
\mathbf{F}_{t-1} \\
\mathbf{X}_{t-1}
\end{array}\right)+\left(\begin{array}{c}
\varepsilon_{t}^{F} \\
\varepsilon_{t}^{X}
\end{array}\right)
$$

where

$$
\left(\begin{array}{c}
\varepsilon_{t}^{F} \\
\varepsilon_{t}^{X}
\end{array}\right)=\left(\begin{array}{c}
\mathbf{I} \\
\Lambda
\end{array}\right) \boldsymbol{\eta}_{t}+\left(\begin{array}{c}
\mathbf{0} \\
\mathbf{v}_{t}
\end{array}\right)
$$

with variance covariance matrix

$$
E\left(\varepsilon_{t} \varepsilon_{t}^{\prime}\right)=\Sigma_{\varepsilon}=\left(\begin{array}{cc}
\Sigma_{\eta} & \Sigma_{\eta} \Lambda^{\prime} \\
\Lambda \Sigma_{\eta} & \Lambda \Sigma_{\eta} \Lambda^{\prime}+\Sigma_{v}
\end{array}\right)
$$

where $E\left(\boldsymbol{\eta}_{t} \boldsymbol{\eta}_{t}^{\prime}\right)=\boldsymbol{\Sigma}_{\eta}$ and $E\left(\mathbf{v}_{t} \mathbf{v}_{t}^{\prime}\right)=\boldsymbol{\Sigma}_{v}$. The $F-V A R$ form in (3) can be inverted to obtain the vector moving average $(V M A)$ form for the $\mathbf{X}_{t}$ process:

$$
\mathbf{X}_{t}=\mathbf{B}(L) \boldsymbol{\eta}_{t}+\mathbf{C}(L) \mathbf{v}_{t}
$$

where $\mathbf{B}(L)=[\mathbf{I}-\mathbf{D}(L) L]^{-1} \boldsymbol{\Lambda}[\mathbf{I}-\boldsymbol{\Phi}(L) L]^{-1}$ and $\mathbf{C}(L)=[\mathbf{I}-\mathbf{D}(L) L]^{-1}$.

Then, the identification of the structural shocks to the factors in $\mathbf{F}_{t}$ can be carried out starting from the reduced form innovations $\boldsymbol{\eta}_{t}$. By denoting as $\boldsymbol{\xi}_{t}$ the vector of the $r$ structural global shocks, the relation between the reduced form and the structural disturbances can be written as $\boldsymbol{\xi}_{t}=\mathbf{H} \boldsymbol{\eta}_{t}$, where $\mathbf{H}$ is a $r \times r$ invertible matrix. By assumption the structural shocks are orthogonal and have unit variance, so that $E\left[\boldsymbol{\xi}_{t} \boldsymbol{\xi}_{t}^{\prime}\right]=\mathbf{H} \boldsymbol{\Sigma}_{\eta} \mathbf{H}^{\prime}=\mathbf{I}_{r}$. The identification of such disturbances amounts then to the identification of the elements of $\mathbf{H}$. Given $r$ factors, $r(r-1) / 2$ restrictions need to be imposed to obtain exact identification.

Finally, a similar procedure can be used to obtain structural disturbances from the vector of idiosyncratic shocks $\mathbf{v}_{t}$. The $n$-variate vector $\boldsymbol{\psi}_{t}$ contains the idiosyncratic structural shocks and is related to $\mathbf{v}_{t}$ by $\boldsymbol{\psi}_{t}=\boldsymbol{\Theta} \mathbf{v}_{t}$, where $\Theta$ is a $n \times n$ invertible matrix. These (unit variance) structural disturbances are orthogonal and uncorrelated with the structural factor shocks, so that $E\left(\boldsymbol{\psi}_{t} \psi_{t}^{\prime}\right)=\boldsymbol{\Theta} \boldsymbol{\Sigma}_{\boldsymbol{\eta}} \boldsymbol{\Theta}^{\prime}=\mathbf{I}$ and $E\left(\psi_{i, t} \xi_{j, t}\right)=0$ for all $i$ and $j$. Imposing a set of $n(n-1) / 2$ restrictions allows exact identification of the elements of $\boldsymbol{\Theta}$. The structural $V M A$ representation of the dynamic factor model then becomes

$$
\mathbf{X}_{t}=\mathbf{B}^{*}(L) \boldsymbol{\xi}_{t}+\mathbf{C}^{*}(L) \boldsymbol{\psi}_{t}
$$

where $\mathbf{B}^{*}(L)=\mathbf{B}(L) \mathbf{H}^{-1}$ and $\mathbf{C}^{*}(L)=\mathbf{C}(L) \boldsymbol{\Theta}^{-1}$ describe the impulse response functions of each variable in $\mathbf{X}_{t}$ to the structural global and idiosyncratic shocks respectively. 
In order to estimate the $F-V A R$ model (3) and the structural disturbances in (5) we adopt a variant of the two-step procedure outlined in Stock and Watson (2005a), described in detail in what follows. First, estimates of the common factors $\left\{\mathbf{F}_{t}\right\}$ and their innovations $\left\{\boldsymbol{\eta}_{t}\right\}$ are obtained by principal components methods. Then, identifying restrictions are imposed to estimate structural factor and idiosyncratic disturbances and the associated structural impulse response functions. ${ }^{6}$

\subsubsection{Common factor estimation}

In the first step, estimates of the common factors $\left\{\mathbf{F}_{t}\right\}$ and the associated loadings $\boldsymbol{\Lambda}$ are obtained by solving iteratively the following minimization problem

$$
\min _{F_{1}, \ldots, F_{T, \Lambda}, D(L)} T^{-1} \sum_{t=1}^{T}\left[(\mathbf{I}-\mathbf{D}(L) L) \mathbf{X}_{t}-\mathbf{\Lambda} \mathbf{F}_{t}\right]^{\prime}\left[(\mathbf{I}-\mathbf{D}(L) L) \mathbf{X}_{t}-\mathbf{\Lambda} \mathbf{F}_{t}\right]
$$

where $T$ is the sample size. Given a preliminary estimate of $\mathbf{D}(L)$, the common factors can be estimated as the principal components of the filtered variables $(\mathbf{I}-\mathbf{D}(L) L) \mathbf{X}_{t}$. Then, conditional on the estimated factors, an estimate of $\boldsymbol{\Lambda}$ and an updated estimate of $\mathbf{D}(L)$ can be obtained by OLS from (1). This procedure is then iterated until convergence. Once the final estimate of $\left\{\mathbf{F}_{t}\right\}$ is available, the $\boldsymbol{\Phi}(L)$ matrix is obtained by applying OLS to (2). Finally, by also employing the final estimates of $\boldsymbol{\Lambda}$ and $\mathbf{D}(L)$, the restricted VAR coefficients in (3) can be obtained.

In order to obtain estimates of the common factors, the principal components analysis could be applied directly to the whole set of variables in $\mathbf{X}_{t}$, with the number of factors selected by the information criteria of Bai and $\mathrm{Ng}$ (2002). This method, followed among others by Bernanke and Boivin (2003), Bernanke, Boivin and Eliasz (2005) and Stock and Watson (2005a), exploits all available information in the observed series, but makes the economic interpretation of the factors difficult. Since the interpretability of the factors is essential to the purpose of our investigation, we adopt a different strategy. Following the lead in Bernanke and Boivin (2003), we divide our data set into categories of variables and estimate the factors separately as the first principal component for each sub-set of series. For example, a "global output growth factor" is estimated as the first principal component from the

\footnotetext{
${ }^{6}$ The model could be estimated in one step by Gaussian Maximum Likelihood using the Kalman filter. However, as argued by Stock and Watson (2005a), the two-step approach is not subject to convergence problems and is preferable when the number of processes is large.
} 
set of the GDP growth rates of the countries under study; a "global stock price factor" is obtained in the same way from the set of the rates of change in real stock prices, and so on. Therefore, the $r$ static factors in $\mathbf{F}_{t}$ are separately estimated as the first principal components from the relevant sub-sets of variables, each including $m$ series. This estimation procedure can make it easier to give an economic content to the factors and is applied in each step of the iteration process described above.

\subsubsection{Identification of structural disturbances}

The second stage of the methodology addresses the issue of the identification of the structural factor disturbances in $\boldsymbol{\xi}_{t}$ from the factor innovations in $\boldsymbol{\eta}_{t}$. To this aim, we employ a standard identification scheme in structural VAR models, based on exclusion restrictions on the contemporaneous (within quarter) responses of the $r$ factors in $\mathbf{F}_{t}$ to the global structural shocks. Since $\boldsymbol{\eta}_{t}=\mathbf{H}^{-1} \boldsymbol{\xi}_{t}$, this amounts to imposing zero restrictions on the elements of the matrix $\mathbf{H}^{-1}$, for which we assume a lower-triangular structure. This assumption implies a precise "ordering" of the common factors in $\mathbf{F}_{t}$. As described in the previous subsection, the method we use to extract common factors from sub-sets of variables capturing different dimensions of the economy (output, inflation, etc.) allows for a more direct interpretation of the estimated factors. We exploit this feature of our methodology by choosing an ordering based on plausible assumptions on the relative speed of adjustment to shocks: we order first the factors related to relatively slowmoving variables (output growth, inflation) followed by the factors extracted from relatively fast-moving variables (money growth, interest rates, the exchange rate, the oil price, and stock returns). Hence, for instance, the output growth factor (ordered first) is allowed to have a contemporaneous impact on all other factors, but reacts only with a one-period lag to the other structural disturbances; instead, the stock return factor (ordered last) is affected contemporaneously by all structural shocks, having only lagged effects on all other factors. Operationally, $\mathbf{H}^{-1}$ (with the $r(r-1) / 2$ zero restrictions necessary for exact identification imposed) is estimated by the Choleski decomposition of the factor innovation variance matrix $\boldsymbol{\Sigma}_{\eta}: \hat{\mathbf{H}}^{-1}=\operatorname{chol}\left(\hat{\boldsymbol{\Sigma}}_{\eta}\right){ }^{7}$

Finally, the identification of the structural idiosyncratic shocks in $\boldsymbol{\psi}_{t}$ is

\footnotetext{
${ }^{7}$ Several alternative identification strategies are available, based for example on contemporaneous timing restrictions on the responses of the variables in $\mathbf{X}_{t}$ to the structural factor disturbances (Bernanke, Boivin and Eliasz, 2005), on long-run restrictions (Giannone, Reichlin and Sala, 2002) or on restrictions on the factor loadings (Kose, Otrok and Whiteman, 2003, and Boivin and Giannoni, 2005). See Stock and Watson (2005a) for details.
} 
obtained by imposing exclusion restrictions on their contemporaneous impact on the variables in $\mathbf{X}_{t}$. From the structural VMA representation of the model in (5), this requires the identification of the elements of the $n \times n$ matrix $\mathbf{C}_{0}^{*}=\mathbf{\Theta}^{-1}$. To this aim, we first exploit the distinction between slowmoving and fast-moving variables introduced above and order the elements of $\mathbf{X}_{t}$ and $\boldsymbol{\psi}_{t}$ into $r$ stacked sub-vectors, with the slow-moving variables (and the corresponding disturbances) in the upper position followed by the fast-moving variables in the same order used above. Each sub-vector has $m$ elements, containing the same variable for the $m$ countries (or regions) under study. Within each sub-vector, the countries are ordered in terms of GDP size, placing the relatively large region first (the US, Japan, and the Euro-12 area), followed by the smaller countries (the UK and Canada).

Then, the elements of $\mathbf{C}_{0}^{*}$ are identified by imposing a lower triangular structure of the form:

$$
\mathbf{C}_{0}^{*}=\left(\begin{array}{ccc}
\mathbf{C}_{0_{11}}^{*} & \cdots & \mathbf{0} \\
\vdots & \ddots & \vdots \\
\mathbf{C}_{0_{r 1}}^{*} & \cdots & \mathbf{C}_{0_{r r}}^{*}
\end{array}\right)
$$

where each block $\mathbf{C}_{0_{i j}}^{*}$ has dimension $m \times m$. This structure implies that structural idiosyncratic shocks to relatively "faster" variables (in any country) have no contemporaneous impact on "slower" variables (in any country). Moreover, we impose a lower triangular structure also on each block on the main diagonal of $\mathbf{C}_{0}^{*}$, i.e. (for $j=1, \ldots r$ )

$$
\mathbf{C}_{0_{j j}}^{*}=\left(\begin{array}{ccc}
c_{0_{j j, 11}}^{*} & \cdots & 0 \\
\vdots & \ddots & \vdots \\
c_{0_{j j, m 1}}^{*} & \cdots & c_{0_{j j, m m}}^{*}
\end{array}\right)
$$

which implies that structural idiosyncratic disturbances to relatively "smaller" regions do not have impact effects on "larger" economies. Hence, for instance, the block $\mathbf{C}_{0_{11}}^{*}$ contains the impact responses of the GDP growth rates for the various regions (in the order: US, Japan, the Euro area, the UK and Canada) to region-specific structural shocks to GDP growth.

Operationally, the estimation of the $\mathbf{C}_{0}^{*}=\boldsymbol{\Theta}^{-1}$ matrix is carried out as follows. First, the estimate of the $F-V A R$ innovations $\hat{\varepsilon}_{t}^{X}$ from (3) is regressed on $\hat{\boldsymbol{\xi}}_{t}$ by OLS to obtain an estimate of the idiosyncratic disturbances, $\hat{\mathbf{v}}_{t}$. Then, $\boldsymbol{\Theta}^{-1}$ (with the $n(n-1) / 2$ zero restrictions necessary for exact identification imposed) is estimated by the Choleski decomposition of the idiosyncratic shocks variance matrix $\boldsymbol{\Sigma}_{v}: \hat{\boldsymbol{\Theta}}^{-1}=\operatorname{chol}\left(\hat{\boldsymbol{\Sigma}}_{v}\right)$.

The sensitivity of the empirical results to different orderings of the variables in the identification strategy of both the common factor and the idiosyncratic structural disturbances can be assessed by following a thick modelling 
estimation approach (Granger and Jeon, 2004) and computing generalized impulse response functions (Pesaran and Shin, 1998).

\subsection{Discussion}

The proposed methodology can be considered as a special case of the FVAR approach of Stock and Watson (2005a), holding when there is an equal number of static and dynamic factors. Differently from Stock and Watson, we extract global factors from sub-sets of variables capturing different features of the economy, rather than from the entire data set; this approach has the advantage of allowing for a more clear-cut interpretation of the global shocks. We also explicitly address the issue of the identification of all structural country-specific disturbances.

Concerning our estimation procedure, the use of the principal components estimator in the case of persistent processes is based on recent theoretical developments due to Bai $(2002,2003)$ and Bai and $\mathrm{Ng}$ (2004), allowing to treat the unobserved factors as if they were known in estimation of the F-VAR model, as well as for an accurate estimation of the factors themselves in the current framework. ${ }^{8}$ Moreover, differently from the F-VAR approach of Giannone, Reichlin and Sala (2002), Favero, Marcellino and Neglia (2005) and Bernanke, Boivin and Eliasz (2005), the proposed method has the advantage of using an iterated estimation procedure, recovering asymptotically full efficiency, in addition to granting consistency and asymptotic normality, also allowing the imposition of appropriate restrictions concerning the lack of Granger causality of the variables versus the factors, as in Stock and Watson (2005a).

In addition, relatively to the approach employed by Pesaran, Schuermann and Weiner (2004) and Dees, di Mauro, Pesaran and Smith (2006) to study the international transmission of shocks, we model all variables as endogenous from the outset, instead of modelling each country separately, with for-

\footnotetext{
${ }^{8}$ In particular, Bai (2003) considers the generalization of the principal components analysis to the case in which the series are weakly dependent processes, establishing consistency and asymptotic normality when both the unobserved factors and the idiosyncratic components show limited serial correlation, and the latter also display heteroschedasticity in both their time-series and cross-sectional dimensions. In Bai (2002) consistency and asymptotic normality is derived in the case of $\mathrm{I}(1)$ unobserved factors and $\mathrm{I}(0)$ idiosyncratic components, also allowing for heteroschedasticity in both the time-series and cross-sectional dimensions of the latter component. Moreover, Bai and Ng (2004) have established consistency also for the case of I(1) idiosyncratic components. As pointed out by Bai and $\mathrm{Ng}$ (2004), consistent estimation should also be achieved by principal components techniques in the intermediate case of long-memory processes, and Monte Carlo results reported in Morana (2006) support this conclusion.
} 
eign variables treated as weakly exogenous. Moreover, in our framework the unobservable factors can be interpreted as global factors, while in Pesaran, Schuermann and Weiner (2004) the interpretation is less straightforward.$^{9}$ Finally, while in our approach the weighting in the construction of the common factors is chosen optimally (by using principal components analysis), in Pesaran, Schuermann and Weiner (2004) the weighting is somewhat arbitrary, albeit based on sound economic justifications.

\section{The data}

The analysis of this paper covers four countries, namely the United States, Japan, the United Kingdom and Canada, and one large economic region, made up by the 12 European countries that adopted the euro (the "euro area", henceforth labelled $E A$ ). For each country (or region) a set of eight core macroeconomic variables is studied, comprising real GDP, the CPI price index, nominal long-term and short-term interest rates (ten-year government bond yields and three-month government bill rates, respectively), nominal money balances, the real effective exchange rate, the real equity price (obtained from broad stock market indices), and the real oil price. The last three variables are obtained from the corresponding nominal quantities using the CPI as deflator. ${ }^{10}$

The chosen set of variables, capturing both real and nominal dimensions of the economy, is very close to that used by Dees, di Mauro, Pesaran and Smith (2006), but includes also a monetary aggregate to investigate the effects of various global and country-specific shocks on the economies' liquidity conditions, and the links between monetary dynamics and fluctuations in inflation and output. To this aim, we select the aggregates usually employed to measure broad money (see, for example, Sousa and Zaghini, 2004), such as $M 3$ for the euro area and Canada, $M 4$ for the UK, and $M 2$ plus certificates of deposits for Japan; for the US we use $M 2$, since broader aggregates do not seem to add useful information about economic activity and have not been used in the monetary policy decision-making process for a long time. ${ }^{11}$

\footnotetext{
${ }^{9}$ In fact, what is denoted as global factor in Pesaran, Schuermann and Weiner (2004) is just a summary feature for all the variables which may have an impact on a given country, but for parsimony reasons are not modelled in detail. This is because when the unobserved component is estimated, the own country variables are neglected. However, it is hard, for instance, to justify the exclusion of US data when the global factors for the US are computed.

${ }^{10}$ The source of the euro-area aggregate data is the European Central Bank. All other data are taken from Datastream.

${ }^{11}$ This is the basis of the November 2005 announcement by the Federal Reserve of the
} 
All series are sampled at a quarterly frequency and seasonally adjusted when appropriate.

The sample period starts in 1980(1) and ends in 2005(2). The choice of the time span has a twofold motivation. First, data availability. Over this period homogeneous series across countries can be gathered, and reliable euro-area aggregates are available. Second, as already mentioned in the introduction, there is ample evidence of a change in the pattern of common cyclical fluctuations among the major world's economies and a reduction in the degree of synchronization in the 1980s and 1990s with respect to the preceding decades (Stock and Watson 2003 and 2005b, among others). Focusing on the post-1980 period can therefore reduce the possibility of parameter instability problems in estimation.

\subsection{Persistence properties}

The persistence properties of the data are extensively assessed by means of a battery of unit roots tests. Both the standard $A D F$ test (Said and Dickey, 1984), which assumes difference stationarity under the null, and the KPSS test (Kwiatkowski, Phillips, Schmidt and Shin, 1992), which assumes stationarity around either a constant term or a constant plus a linear deterministic trend, are employed. Moreover, in order to allow for an adaptive non linear trend, also the Enders and Lee (2005) $A D F$ test and a modified version of the KPSS test have been performed. In those tests the deterministic component $\mu_{t}$ is modelled by means of the Gallant (1984) flexible functional form, whereby $\mu_{t}=\mu_{0}+\mu_{1} t+\mu_{2} \sin (2 \pi t / T)+\mu_{3} \cos (2 \pi t / T)$. That function can capture not only a deterministic process of gradual change in a time-varying intercept, but also the presence of sharp breaks and of various forms of non linear trends (Enders and Lee 2005). ${ }^{12}$

The tests have been carried out directly on the series used in the empirical analysis, i.e. the growth rate of real GDP (denoted by $g$ ), the rate of inflation $(\pi)$, the levels of the long-term and short-term nominal interest rates ( $l$ and $s$, respectively), the nominal money growth rate $(m)$, and the rates of change of the real effective exchange rate $(e)$, the real stock price $(f)$, and the real price of oil $(o)$. These definitions are consistent with the aim of our study, which is the investigation of global macroeconomic dynamics, and allow to overcome

dismissal of $M 3$ as a monetary indicator. From March 2006 the Board of Governors ceased even to report this aggregate.

${ }^{12}$ Critical values of the $A D F$ test with the adaptive non linear trend are provided by Enders and Lee (2005). In the case of the KPSS test, critical values have been tabulated by means of Monte Carlo simulations with 10000 replications and are very close to those reported in Becker, Enders and Lee (2006). 
the problem of a different unit of account across countries for some of the variables considered. In fact, while one would not be allowed to extract a global factor, for instance, from the GDP series in levels, unless all the series are previously expressed in the same units of account, the use of growth rates avoids such a shortcoming. Moreover, the size of a country does not have an impact on the results if growth rates are employed.

Table 1 reports the results of the $A D F$ and $K P S S$ unit root tests for the three different specifications of the deterministic component mentioned above. As far as the real variables are concerned (GDP growth, real equity returns, and the rates of change of the real exchange rate and the real oil price) the two types of test yield consistent results, strongly pointing to the rejection of $I(1)$ non-stationarity and to the non rejection of the null of $I(0)$ stationarity, with only one notable exception. In fact, only for Japan's output growth the tests yield conflicting results (rejecting both the $I(1)$ and $I(0)$ null hypotheses). In this case, the rejection of stationarity detected by the KPSS test may be due to the sharp slowdown of economic growth in Japan at the beginning of the 1990s: once the more flexible Enders-Lee specification of the deterministic trend is adopted, the null of $I(0)$ stationarity is not rejected any longer, as shown by the value of the $K P S S_{n l t}$ test in the last column of the table. ${ }^{13}$

The unit root tests deliver less clear-cut results for the remaining variables. Two main findings stand out. First, as far as the nominal interest rates are concerned, the results are inconclusive, since in general the $A D F$ tests do not reject the null of $I(1)$ non stationarity (with the notable exception of the long-term US rate), while the KPSS tests never point to the rejection of $I(0)$ stationarity. Second, in the case of nominal money growth and inflation, the null of non stationarity can always be rejected when a non linear trend is accounted for (by $A D F_{n l t}$ tests), apart from nominal money growth in Japan. Yet, when the corresponding $K P S S_{n l t}$ test is considered, while the null of stationarity is never rejected for money growth at the $1 \%$ level, rejections are found for the US, Japan and the euro area.

Economic explanations for the presence of a non linear deterministic trend in nominal variables for the US and the euro area have been suggested by Bierens (2000) and Morana (2006). They note that successful long-run monetary policy management should shape the trend behavior of the nominal variables, and that policy decisions are better understood in terms of a deterministic rather than a stochastic process. For instance, the setting of

\footnotetext{
${ }^{13}$ For all the other output growth series, the test results do not favor the inclusion of a non-linear deterministic trend, providing evidence of structural stability (see Morana (2006) for a more extensive analysis of the euro-area series).
} 
policy interest rates by central banks renders the latter step-wise deterministic processes, allowing to expect the presence of non linear deterministic trends both in the short- and long-term interest rate series.

Moreover, the presence of long memory in the nominal variables, in addition to structural breaks, has been widely documented in the literature (see, for instance, Morana 2006 for the euro area, and Bagliano and Morana 2006 for the US). This feature may actually explain why the KPSS test tends to reject the null of $I(0)$ stationarity for the inflation rate in particular. In fact, deviations of nominal interest rates from their non linear trends may still be strongly persistent, and determined not only by long-memory dynamics but also by short-memory (ARMA) dynamics (Morana 2006).

In this paper we are not concerned with the precise determination of the long-memory characteristics of the series investigated (for which a longer time span with data sampled at a higher frequency and the use of semiparametric estimators would be preferable), since, given the scope of the paper, we may rely on the autoregressive representation of a fractional autoregressive moving average process (ARFIMA) for estimation. Yet, the possible presence of structural breaks in the series is a major concern here. In order to account for this possibility, and on the basis of the unit root test results in Table 1 (especially for nominal money growth and inflation), the stationary representation of the F-VAR model has been augmented by including the adaptive specification for the deterministic component suggested by Enders and Lee $(2005) \cdot{ }^{14}$

\section{Estimating common global macroeconomic factors}

Comovements among core macroeconomic variables of the five countries (or regions) under study are derived by applying principal components $(P C)$ analysis to our dataset. As mentioned in the methodological section, to aid economic interpretability, instead of applying the $P C$ statistical procedure to the entire set of series, we extract the common factors as the first principal components from sub-sets of variables capturing different dimensions of the economy. We start from eight sub-sets of series, each comprising the same variable for the five regions, namely the GDP growth rate, the inflation rate, the short- and the long-term interest rates, the rate of nominal money growth and the real rates of change of the effective exchange rate, of equity prices

\footnotetext{
${ }^{14}$ Hence, the deterministic component included in the $i$ th equation of the $F-V A R$, $\mu_{i, t}$, is specified as $\mu_{i, t}=\mu_{i, 0}+\mu_{i, 1} t+\mu_{i, 2} \sin (2 \pi t / T)+\mu_{i, 3} \cos (2 \pi t / T)$.
} 
and of the real oil price. For each set, Table 2 reports the proportion of the total variance of the series attributable to each $P C_{i}$ (with $\left.i=1, \ldots 5\right),{ }^{15}$ followed by the fraction of the variance of each individual variable explained by each $P C_{i}$.

For the first (and only the first) $P C$ to suitably qualify as a factor capturing international comovements, two requirements must be met: (i) it should explain a sufficiently large fraction of the total variance of the whole variable set relative to additional $P C$ s, and (ii) its relevance should not be limited only to one or two regions but should be evenly spread across countries. The results in Table 2 show that, with the possible exception of the real exchange rate, there is evidence that the first $P C$ s satisfy both criteria. In the case of the GDP growth rates $(g)$, a sizeable fraction of the overall variance $(0.40)$ is attributable to $P C_{1}$, which also captures between one-third and two-thirds of the variance of output growth in all individual regions except for Japan (excluding this country, the average fraction of the variance attributable to $P C_{1}$ rises to 0.50$)$. Moreover, the proportion of total variance attributable to $P C_{2}$ is only 0.23 ; this second component captures mainly fluctuations in Japan's output growth, for which the proportion explained is 0.64 (if Japan is excluded, the average proportion in the remaining countries falls to 0.13). We conclude that the first $P C$ for GDP growth is a valid estimate of a common "output growth factor", affecting all countries in our sample with the exception of Japan; additional $P C$ s capture only country-specific fluctuations and do not qualify as common factors. The mainly idiosyncratic behavior of Japan's output growth is consistent with the long stagnation experienced by this country especially in the 1990s. The upper-left panel of Figure 1 shows the GDP growth rates in the five regions together with the "output growth factor" (the solid thick line). ${ }^{16}$ Similar comments and conclusions apply to real stock returns $(f)$. Here the proportion of the overall variance attributable to $P C_{1}$ is 0.57 , and, again with the exception of Japan, the fractions of the variances of the individual series explained by this component range from 0.55 for the euro area to 0.82 for the US, making $P C_{1}$ a suitable estimate of a global "stock market factor".

Several other variables display even stronger common dynamics. Apart from oil prices, for which a strong comovement of the series is expected, since heterogeneousness is only due to the exchange rate component, the fraction

\footnotetext{
${ }^{15}$ The fraction of the total variance attributed to $P C_{j}$ is given by $\lambda_{j} /\left(\sum_{i=1}^{5} \lambda_{i}\right)$, where $\lambda_{j}$ is the $j$-th largest characteristic root of the sample variance-covariance matrix of the series. The $P C$ analysis has been carried out on the standardized variables.

${ }^{16}$ To smooth out high frequency fluctuations, all series are shown as nine-quarters centered moving averages.
} 
of the overall variance attributable to the first principal component is very large for nominal interest rates $(0.88$ and 0.95 for the short-term and longterm rate respectively) and for the inflation rate (0.70), and sizeable also for nominal money growth (0.49). Within the data sub-sets, $P C_{1}$ explains a large fraction of the variance of the individual interest rate and inflation series. For the latter variable, the results are consistent with the evidence of a global inflation factor provided by Ceccarelli and Mojon (2005), including the relatively lower proportion of the variance of Japanese inflation attributable to $P C_{1}(0.56)$. In all cases additional components seem to capture country-specific fluctuations and not common dynamics. More dispersion across regions is observed for nominal money growth rates: the proportion of the variance attributable to $P C_{1}$ ranges from 0.24 for Canada to 0.75 for the UK. The relevant panels in Figure 1 confirm the strong comovements of those series (less evident in the case of money growth) and display the behavior of the principal component capturing global dynamics. Among the variables analyzed, the real effective exchange rate changes display relatively little evidence of comovements: though the fraction of the variance attributable to $P C_{1}$ is 0.37 for the whole set of series, it shows a wide dispersion across regions and seems heavily influenced by the US series, for which the proportion is 0.76 (excluding the US, the average proportion falls to 0.27 ): on this basis we conclude that there is no compelling evidence pointing to a global factor driving real exchange rates.

The comovements detected in the inflation, interest rates and money growth sub-sets suggest a further step in the investigation of potential common factors. In Table 3 we apply the $P C$ analysis to the whole set of the $\pi$, $s, l$ and $m$ series, reporting the proportion of the variance attributable to the first ten principal components. The results show that as much as two-thirds of the overall variance is attributable to $P C_{1}$, with additional components having a negligible role. Moreover, $P C_{1}$ seems to capture common dynamics in all individual series with the already noted exception of the US and Canadian money growth rates. ${ }^{17}$ In fact, these latter variables display a more idiosyncratic behavior, with a large proportion of their variance being explained by the second and third components for Canada and the US, respectively (with fractions 0.59 and 0.53 ). The common factor extracted from the set of $\pi, s, l$ and $m$ variables is displayed in each panel of Figure 2 together with the five inflation rates, interest rates and money growth rates in turn. As a whole, this set of results points to the existence of a global

\footnotetext{
${ }^{17}$ The proportion of variance attributable to $P C_{1}$ averages at 0.57 for inflation, 0.84 for the short-term interest rate, 0.92 for the long-term interest rate, and 0.35 for nominal money growth.
} 
common factor driving inflation, interests rates and money growth across the regions under study. ${ }^{18}$

Finally, $P C$ analysis is applied to all variables for each individual region and the results reported in Table 4 . Here the first principal component captures mainly the comovements of inflation, interest rates and money growth in each region, explaining a fraction of the overall variance ranging from 0.34 in the US to 0.41 in the UK. Again, the evidence supports the existence of a global factor driving those variables, maybe related to the successful disinflationary monetary policies conducted by the national central banks of several countries in the sample during the 1980s and 1990s, leading to the stabilization of inflation rates at historically low levels.

On the whole, the results of the $P C$ analysis confirm some of the evidence available in the literature, detecting strong international comovements among GDP growth rates, among real stock returns and among inflation rates within G-7 countries. Moreover, we find strong evidence of a common global force driving inflation, monetary aggregates and interest rates, that we label "inflation factor". Then, on the basis of the above results, four global factors have been retained for the $F-V A R$ analysis, namely an "output growth factor", a "stock returns factor", a real "oil price factor", and an "inflation factor". Those estimated factors have been included in the $F-V A R$ model as starting estimates of the elements of vector $\mathbf{F}_{t}$ in the first step of the iterative procedure described in section 2 .

\section{Global and idiosyncratic components in in- ternational macroeconomic dynamics}

In order to investigate the nature and the relative importance of the common factors and the region-specific components in shaping macroeconomic fluctuations in the countries under study, the $F-V A R$ system in (3) is estimated. The iterative estimation procedure starts from the initial estimate of the four common factors obtained in the previous section and delivers estimates of all parameters in the $\boldsymbol{\Lambda}, \mathbf{D}(L)$, and $\boldsymbol{\Phi}(L)$ matrices in (3). On the basis of mis-specification tests, the lag length of the system has been set to one. ${ }^{19}$

\footnotetext{
${ }^{18}$ For completeness, we applied $P C$ analysis also to the data set comprising all remaining variables, namely $g, e, f$ and $o$. In this case the fraction of the overall variance attributable to $P C_{1}$ is only 0.25 , mainly capturing the comovement of the oil price. Overall, the findings point to separate factors for each set of variables, as in the analysis of Table 1.

${ }^{19}$ Evidence of serial correlation at the $1 \%$ significance level is found only in the UK and US output growth equations. Also, significant ARCH effects have been found only for the UK output growth and short term rate equations and for the euro area long term rate
} 
More specifically, the structure of the $F-V A R$ is as follows. The first four equations correspond to the vector of common factors $\mathbf{F}_{t}$ with the following ordering: output growth factor, inflation factor, oil price factor and stock market factor. Each equation contains 8 parameters, of which 4 are for the lagged factor series and 4 are for the deterministic trend (including a constant, a linear and two non linear components, as described in section 3). Vector $\mathbf{X}_{t}$ collects 7 endogenous macroeconomic variables (namely $g$, $\pi, s, l, m, e$, and $f$, in this order) for the 5 regions analyzed (within each variable group, the regions are ordered as: US, Japan, euro area, UK, and Canada). ${ }^{20}$ Each equation corresponding to the 35 elements of $\mathbf{X}_{t}$ has therefore 43 parameters: 35 for the lagged endogenous variables, 4 for the lagged factors, and 4 for the deterministic trend component. The estimation period is $1980(1)-2005(2)$.

In order to obtain structural global and idiosyncratic disturbances from the reduced-form innovations of the $F-V A R$ system, the recursive identification scheme described in section 2 , based on the above mentioned orderings of the common factors and the endogenous variables, is implemented. The structural $V M A$ representation of the model in (5) is then used to perform innovation analysis (deriving forecast error variance decompositions and impulse response functions) to assess the relative importance of global disturbances and region-specific shocks as driving forces of the macroeconomic dynamics across countries, and to characterize the dynamic responses of the endogenous variables in each region to the common global disturbances.

The economic interpretation of the structural shocks to the common factors (i.e. the elements of $\boldsymbol{\xi}_{t}$ in (5)) requires caution, though the procedure used to extract the common factors from selected sub-sets of variables provides useful suggestions. First, the disturbance to the "output growth factor" captures innovations to business cycle comovements; the results of the impulse response analysis described below are consistent with an interpretation in terms of global demand-side shocks. Second, given the strong statistical significance of the non linear deterministic trend in the equation for the common "inflation factor" (capturing a gradual downward trend in the level of inflation rates, interest rates and monetary growth), the associated structural shock captures innovations in the factor dynamics about the deterministic trend component. Since, on the basis of previous evidence in the literature (Bierens 2000, Morana 2006) the latter component is likely to reflect effec-

\footnotetext{
equation.

${ }^{20}$ The $P C$ analysis carried out in the previous section showed that the variance of real oil prices in all regions is almost entirely attributable to a common factor, leaving a negligible role for idiosyncratic components. Therefore, we include the oil price factor as an element of $\mathbf{F}_{t}$, but do not include real oil price changes $(o)$ into the set of $n$ endogenous variables.
} 
tive long-term monetary policy management, the structural disturbance to the inflation factor may reflect other macroeconomic forces. In particular, also in the light of recent results by Gordon (2005) pointing to an important role of productivity growth in determining US inflation dynamics, the structural disturbance to the inflation factor could be related to common supply-side forces. Again, the shape of the impulse response functions to this shock will not be at variance with this interpretation. Finally, the two remaining disturbances capture innovations to the common factors driving real stock returns and real oil price changes.

\section{$5.1 \quad$ Variance decompositions}

The relative contribution of global and idiosyncratic components to the fluctuations of macroeconomic variables in each region is assessed by estimating the share of the forecast error variance of each variable due to the structural common factor disturbances and to the region-specific shocks. Table 5 presents the forecast error variance decomposition for each variable at a short (one-quarter) and a long (five-year) horizons. The table reports the share of the variance due to each of the four common factor disturbances together with their sum; moreover, the proportion of the variance attributable to the own-region ("domestic") idiosyncratic shocks is reported together with the overall share due to both domestic and foreign region-specific disturbances ("all"). ${ }^{21}$ Therefore, the difference between the last two columns captures the importance of "spillover" effects from foreign shocks in shaping the dynamics of domestic variables. ${ }^{22}$

Considering first the overall importance of global disturbances, it appears that in all regions the shocks to the common factors explain a sizeable proportion of the forecast error variance of all variables except for the exchange rate changes, the variance of $e$ being dominated by the idiosyncratic components. The only exception to this regularity is the euro-area: here the proportion of the within-quarter variance explained by the global disturbances is $58 \%$, falling down to $11.5 \%$ at the five-year horizon.

Looking more deeply at the relative contribution of the global shocks,

\footnotetext{
${ }^{21}$ The table reports median forecast error variance decompositions obtained (as the median impulse response functions described below) using Monte Carlo simulation, as suggested in Granger and Jeon (2004). For reasons of space only the results for the within-quarter and five-year horizons are reported; a full set of results is available from the authors upon request.

${ }^{22}$ Our identification scheme allows foreign idiosyncratic shocks to affect domestic variables within tha same quarter, whereas in Stock and Watson (2005b) country-specific disturbances can lead to spillover effects only with at least a one-quarter lag.
} 
from the table it can be noted that the proportion of the forecast error variances attributable to the common factor innovations is entirely due to the first two factors (related to output growth and inflation), whereas the shocks to the stock price and oil price factors explain less than $5 \%$ of the variance for all variables at any horizon. Therefore, the latter factors, though being statistically significant in capturing international comovements of stock returns and real oil price changes, give a negligible contribution to the fluctuations of the macro variables under study. Shocks to the common "inflation factor" explain the bulk of fluctuations in inflation rates, interest rates and nominal money growth for all regions. With the only exception of the euro-area inflation rate $(15 \%)$, the proportion of explained variance at the one-quarter horizon is never lower than $86 \%$, and remains high (over $55 \%$ ) even at the longer horizon. In the case of the euro-area inflation, the domestic idiosyncratic shock explains $75 \%$ of the variance at the one-quarter horizon, whereas the global inflation shock prevails, as in the other countries, at the five-year horizon $(79 \%)$.

Focusing on output dynamics, some differences emerge between the Englishspeaking countries on the one hand and Japan and the euro area on the other, especially at the shorter horizon. In fact, at the one-quarter horizon, global shocks play a larger role in Japan, where they explain as much as $95 \%$ of the variance, and in the euro area (66\%), dominating the idiosyncratic disturbances. Instead, in the US, Canada and the UK domestic shocks are relatively more important: in the first two countries they explain the same proportion of the output variance as the common factor disturbances (around $50 \%$ and $42 \%$, respectively), whereas in the UK they account for as much as $57 \%$ against $28 \%$ attributed to the global shocks. Differences are less pronounced at the five-year horizon, since, in the English-speaking countries, the variance explained by idiosyncratic domestic shocks falls within the 15\%-25\% range, as the role of the global disturbances becomes more relevant (the proportion of explained variance increases in all countries, reaching $39 \%$ in the UK, $57 \%$ in Canada and $63 \%$ in the US). Within the proportion of output variances attributable to global disturbances, we find a relatively balanced role for the shocks to the output growth and to the inflation factors in the US and Canada, whereas the latter common factor shock is more relevant in Japan, UK and in the euro area.

Finally, global shocks explain the bulk of fluctuations in real stock returns in the US and UK (in the range $73-80 \%$ in the former and $78-87 \%$ in the latter country over the two horizons), have a sizeable role in the euro area (53-57\%), but account for a relatively lower fraction of the variance in Japan (32-25\%) and in Canada (24-36\%), where stock returns seem more affected by idiosyncratic disturbances. Moreover, except for Canada where disturbances 
to the output growth factor prevail, the relevance of the global disturbances is mainly due to inflation factor shocks.

Overall, our findings are broadly consistent with several results in the previous literature, and make some additional contributions. In particular, the important role of global shocks in explaining output fluctuations since the 1980s detected by Stock and Watson (2005b) is confirmed, and further qualified, since our analysis allows to disentangle the contribution of global output growth and inflation disturbances, and to account for the role of idiosyncratic shocks. Moreover, the evidence that output fluctuations are importantly determined by a small number of common factors is consistent with the findings of Kose, Otrok and Whiteman (2003). And, differently from Canova and de Nicolò (2003), these findings point out that the synchronization of the G-7 business cycle also depend on common sources of shocks, rather than only on similarities in the transmission mechanism. Also some evidence of a cluster of English-speaking countries, as in Helbling and Bayoumi (2003), is found, though limited only to some of the variables (especially output growth) at the shorter horizon. Finally, as in Stock and Watson (2005b), we find a negligible role for global oil price shocks (and global stock market disturbances) in shaping common international macroeconomic fluctuations.

\subsection{Impulse response functions}

As a further step of the analysis, differences and commonalities across regions in the transmission mechanism of the two major common factor shocks may be assessed by means of the impulse response functions. Moreover, the dynamic responses of the endogenous variables to the output growth and inflation disturbances may shed some light on the economic interpretation of the global shocks. To this aim, Figures 3 to 7 display, for each region, the median impulse responses of the seven macroeconomic variables to a onestandard deviation shock to the output growth factor (in the plots of the first two rows) and to the inflation factor (in the last two rows) over a tenyear horizon; 95\% confidence bands (obtained by Monte Carlo simulation) are also shown. Apart from the interest rate series, the impulse responses have been cumulated over time, to show the dynamic reaction of the level of output, the price level, the short-term and long-term interest rates, the level of the nominal money aggregate, the real effective exchange rate, and the real stock market index.

Several facts stand out. A positive global output shock increases permanently the level of GDP in all regions and, with only one exception, has also a permanent positive effect on the price level: these responses are consistent with the interpretation of the global output shock as capturing demand-side 
disturbances. The exception is represented by the Japanese price level, which responds with a temporary decrease (that becomes not statistically significant after about one year) to a positive global output disturbance. ${ }^{23}$ In all regions, following the shock, nominal money aggregates increase permanently (though not significantly in the euro area), and both the short-term and the long-term interest rates show a temporary rise, that may reflect a (restrictive) monetary policy reaction, leading to a fall in stock prices (the latter effect being not statistically significant in Japan). Finally, the real exchange rate features a prolonged depreciation in the US and Canada, and an opposite behavior in the remaining three regions, with only a short-lived appreciation in the euro area.

As previously discussed, a tentative interpretation of the global inflation shock as capturing supply-side forces, such as productivity disturbances, can be provided, since it represents deviations from a common downward trend in the inflation rate and interest rates mainly attributable to monetary policy management. The responses of output and prices to a global inflation shock are not at variance with this interpretation. In the face of an unexpected increase in the global inflation factor, output decreases and the price level increases permanently in all regions, with the only exception of Japan for the latter variable. Interest rates react with a temporary rise, and money balances increase permanently (though not significantly in the euro area). No other significant effects are found, except for a negative reaction of UK stock prices. ${ }^{24}$

On the whole, the above results point to a broadly similar transmission mechanism of global disturbances across regions, with the notable exception of Japan. The latter country displays a more idiosyncratic behavior that might be consistent with the structural change brought about by the long period of stagnation suffered by Japan during most of the 1990s. ${ }^{25}$

\footnotetext{
${ }^{23}$ This latter finiding is likely related to the deflation affecting Japan since the mid 1980s.

${ }^{24}$ Results for the impulse responses to the oil and stock market global shocks are available upon request from the authors. In short, the response to an oil price shock is consistent with the expected effects of a negative supply side disturbance, leading to an increase in production costs, a contraction in real output and in real stock prices, and an increase in the price level. Evidence of monetary accommodation of the shock is also found. On the other hand, the responses to a positive global stock market shock are consistent with significant wealth/Tobin's "Q" effects, leading to a permanent increase in real stock prices, output and the price level.

${ }^{25}$ The robustness of the impulse response results to the variable ordering has been assessed by computing generalized impulse response functions (Pesaran and Shin 1998). We have found that the orthogonal impulse responses are robust, since there is only one case (the reaction of US GDP to the global output disturbance) in which the response
} 


\section{Conclusions}

In this paper international comovements among a set of key real and nominal macroeconomic variables have been investigated for the G-7 countries, over the 1980-2005 period, using a new Factor Vector Autoregressive approach based on Stock and Watson (2005b).

There is strong evidence of international comovements not only among GDP growth rates (as extensively documented in the literature), but also among real stock returns and among inflation rates; moreover, a common global factor drives inflation, interest rates and monetary aggregates. Shocks to both the output growth common factor and the inflation factor play an important role in explaining international output fluctuations, whereas other common driving forces, such as the common stock market factor and oil price factor give only a negligible contribution to overall macroeconomic dynamics. The responses of the macroeconomic variables to structural disturbances to the output growth and to the inflation factors are broadly consistent with the interpretation of the first one as mainly demand-determined, and of the second one as reflecting supply-side forces, determining deviations from a common downward trend in inflation rates, interest rates, and monetary growth rates mainly attributable to monetary policy management. The analysis of the impulse response functions also points to a broadly similar transmission mechanisms of global disturbances across regions, with the only notable exception of Japan, that displays a more idiosyncratic behavior.

\section{References}

[1] Bagliano, F.C. and C. Morana (2006) "Inflation and monetary dynamics in the US: a quantity-theory approach", Applied Economics, forthcoming

[2] Bai J. (2002) "Estimating cross-section common stochastic trends in nonstationary panel data", Boston College, mimeo

[3] Bai, J. (2003) "Inferential Theory for Factor Models of Large Dimensions", Econometrica, 71, 135-171

[4] Bai, J. and S. Ng (2002) "Determining the Number of Factors in Approximate Factor Models", Econometrica, 70, 191-221

changes sign when generalized, rather than orthogonal, impulse responses are computed. In all other cases, the orthogonal and generalized impulse responses yield qualitatively very similar results, never statistically different at the $5 \%$ significance level. 
[5] Bai, J. and S. Ng (2004) "A Panick Attack on Unit Roots and Cointegration", Econometrica, 72(4), 1127-1177

[6] Becker R., W. Enders and J. Lee (2006) "A Stationarity Test in the Presence of an Unknown Number of Smooth Breaks", Journal of Time Series Analysis, 27, 381-409

[7] Bernanke B.S. and J. Boivin (2003) "Monetary policy in a data-rich environment", Journal of Monetary Economics, 50, 525-546

[8] Bernanke B.S., J. Boivin and P. Eliasz (2005) "Measuring the effects of monetary policy: a factor-augmented vector autoregressive (FAVAR) approach", Quarterly Journal of Economics, 120, 387-422

[9] Bierens, H.J. (2000) "Non Parametric Nonlinear Cotrending Analysis, with an Application to Interest and Inflation in the United States, Journal of Business and Economic Statistics, 18, 323-37.

[10] Boivin J. and M.P. Giannoni (2005) "DSGE Models in a Data-Rich Environment", Columbia University, mimeo

[11] Canova F., M. Ciccarelli and E. Ortega (2004) "Similarities and Convergence in G-7 Cycles", ECB working paper n. 312, forthcoming in Journal of Monetary Economics

[12] Canova F. and G. de Nicolò (2003) "On the Sources of Business Cycles in the G-7", Journal of International Economics, 59, 77-100

[13] Ciccarelli, M. and B. Mojon (2005) "Global Inflation", ECB working paper n. 537

[14] Dees, S., F. di Mauro, M.H. Pesaran and V. Smith (2005) "Exploring the International Linkages of the Euro Area: a Global VAR analysis", Journal of Applied Econometrics, forthcoming

[15] Doyle, B.M. and J. Faust (2002) "An Investigation of Co-movements among the Growth Rates of the G-7 countries", Federal Reserve Bullettin, October, 427-37

[16] Doyle, B.M. and J. Faust (2005) "Breaks in the Variability and Comovement of G-7 economic growth", Review of Economics and Statistics, 87, 721-740 
[17] Ehrmann, M., M. Fratzscher and R. Rigobon (2005) "Stocks, Bonds, Money Markets and Exchange Rates: Measuring International Financial Transmission", NBER working paper, n. 11166

[18] Enders, W. and J. Lee (2005) "Testing for a Unit-Root with a Non Linear Fourier Function", University of Alabama, mimeo

[19] Favero C.A., M. Marcellino and F. Neglia (2005) "Principal components at work: the empirical analysis of monetary policy with large data sets", Journal of Applied Econometrics, 20, 603-620

[20] Gallant, R. (1984) "The Fourier Flexible Form", American Journal of Agicultural Economics, 66, 204-08

[21] Giannone D., L. Reichlin and L. Sala (2002) "Tracking Greenspan: systematic and unsystematic monetary policy revisited", CEPR Discussion paper n. 3550

[22] Gordon, R.J. (2005) "What Caused the Decline in U.S. Business Cycle Volatility?", NBER working paper n. 11777

[23] Granger, C.W. and Y. Jeon (2004) "Thick modelling", Economic Modelling, 21, 323-43

[24] Helbling, T. and T. Bayoumi (2003) "Are They All in the Same Boat? The 2000-2001 Growth Slowdown and the G-7 Business Cycle Linkages", IMF working paper $03 / 46$

[25] Kose, M.A., C. Otrok, C. and C.H. Whiteman (2003) "International Business Cycles: World, Regions and Country-Specific Factors", American Economic Review, 94, 1216-1239

[26] Kose, M.A., Otrok, C. and C.H. Whiteman (2005) "Understanding the Evolution of World Business Cycles", IMF working paper 05/211

[27] Kwiatkowski, D., P.C.B. Phillips, P. Schmidt and Y. Shin (1992) "Testing the Null Hypothesis of Stationarity Against the Alternative of a Unit Root", Journal of Econometrics, 54, 159-78

[28] Monfort, A., J.R. Renne, R. Rufle, and G. Vitale (2003) "Is Economic Activity in the G-7 Sinchronized? Common Shocks vs. Spillover Effects", CEPR discussion paper n. 4119

[29] Morana, C. (2006) "A Small Scale Macroeconometric Model for the Euro-12 Area", Economic Modelling, 23, 391-426 
[30] Morana, C. and A. Beltratti (2006) "Comovements in International Stock Markets", Journal of International Financial Markets Institutions and Money, forthcoming

[31] Pesaran, M.H., Schuermann T. and S.M. Weiner (2004) "Modelling regional interdependencies using a global error correcting macroeconometric model", Journal of Business and Economic Statistics, 22, 129-62

[32] Pesaran, M.H. and Y. Shin (1998) "Generalised impulse response analysis in linear multivariate models", Economics Letters, 58, 17-29

[33] Said, S. and D. A. Dickey (1984) "Testing for Unit Roots in Autoregressive Moving Average Model of Unknown Order", Biometrika, 71, $559-607$

[34] Sousa, J. and A. Zaghini (2004) "Monetary Policy Shocks in the Euro Area and Global Liquidity Spillovers", ECB working paper series n. 309

[35] Stock, J.H. and M.W. Watson (2003) "Has the Business Cycle Changed? Evidence and Explanations", in Monetary Policy and Uncertainty: Adapting to a Changing Economy, Federal Reserve Bank of Kansas City, $9-56$

[36] Stock, J.H. and M.W. Watson (2005a) "Implications of Dynamic Factor Models for VAR Analysis", NBER working paper n. 11467

[37] Stock, J.H. and M.W. Watson (2005b) "Understanding Changes in International Business Cycle Dynamics", Journal of the European Economic Association, 3, 968-1006 
Table 1

Unit-root tests

\begin{tabular}{|c|c|c|c|c|c|c|}
\hline & $A D F_{m}$ & $A D F_{t}$ & $A D F_{n l t}$ & $K P S S_{m}$ & $K P S S_{t}$ & $K P S S_{n l t}$ \\
\hline$g_{U S}$ & $-3.82^{* *}$ & $-3.53^{* *}$ & $-6.86^{* *}$ & $\overline{0.12}$ & $\overline{0.08}$ & $\overline{0.07 *}$ \\
\hline$g_{J A}$ & $-8.15^{* *}$ & $-8.90 * *$ & $-10.04^{* *}$ & $0.87^{* *}$ & $0.16^{*}$ & 0.04 \\
\hline$g_{E A}$ & $-8.02 * *$ & $-8.18^{* *}$ & $-8.01 * *$ & 0.20 & 0.18 & $0.09 * *$ \\
\hline$g_{U K}$ & $-6.49 * *$ & $-6.49^{* *}$ & $-6.48 * *$ & 0.20 & 0.10 & $0.09^{* *}$ \\
\hline$g_{C A}$ & $-5.96 * *$ & $-5.93^{* *}$ & $-5.46 * *$ & 0.09 & 0.05 & 0.05 \\
\hline$\pi_{U S}$ & $-8.07 * *$ & $-8.60 * *$ & $-7.68^{* *}$ & "1.31** & 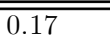 & $\overline{0.08^{* *}}$ \\
\hline$\pi_{J A}$ & -2.86 & $-3.52^{*}$ & $-8.79 * *$ & $0.49^{*}$ & 0.14 & $0.12^{* *}$ \\
\hline$\pi_{E A}$ & $-3.37^{*}$ & -2.84 & $-7.55^{* *}$ & 0.26 & 0.09 & $0.10^{* *}$ \\
\hline$\pi_{U K}$ & $-3.45 * *$ & -3.37 & $-5.01 * *$ & $0.86^{* *}$ & 0.08 & 0.05 \\
\hline$\pi_{C A}$ & $-6.93 * *$ & $-7.95^{* *}$ & $-6.98 * *$ & 0.44 & 0.10 & 0.04 \\
\hline$s_{U S}$ & -1.52 & -2.92 & -3.89 & 0.39 & 0.05 & 0.02 \\
\hline$s_{J A}$ & -1.53 & -2.37 & -3.57 & 0.35 & 0.01 & 0.01 \\
\hline$s_{E A}$ & -1.17 & -2.36 & -2.81 & 0.35 & 0.03 & 0.02 \\
\hline$s_{U K}$ & -1.13 & -2.04 & -2.80 & 0.24 & 0.04 & 0.04 \\
\hline$s_{C A}$ & -1.66 & $-4.27^{* *}$ & -2.90 & 0.19 & 0.03 & 0.03 \\
\hline$\overline{l l_{U S}}$ & -2.20 & $-4.26^{* *}$ & $-5.80^{* *}$ & 0.27 & $\bar{~} 0.07$ & $\overline{c 0.02}$ \\
\hline$l_{J A}$ & -1.73 & -2.06 & -2.14 & 0.33 & 0.03 & 0.03 \\
\hline$l_{E A}$ & -1.56 & -3.16 & -3.57 & 0.37 & 0.02 & 0.02 \\
\hline$l_{U K}$ & -1.17 & -2.79 & -3.66 & 0.24 & 0.03 & 0.03 \\
\hline$l_{C A}$ & -2.08 & $-4.88^{* *}$ & $-4.91^{*}$ & 0.20 & 0.05 & 0.03 \\
\hline$\overline{m_{U S}}$ & $-5.39^{* *}$ & $-5.45^{* *}$ & $-7.72^{* *}$ & $\overline{0.41}$ & $\overline{0.25^{* *}}$ & $\overline{0.07^{*}}$ \\
\hline$m_{J A}$ & -1.95 & -3.02 & -4.16 & 0.28 & 0.10 & 0.06 \\
\hline$m_{E A}$ & -2.39 & -2.15 & $-7.48^{* *}$ & 0.35 & 0.13 & 0.04 \\
\hline$m_{U K}$ & -2.35 & -1.90 & $-6.06^{* *}$ & 0.40 & 0.05 & 0.03 \\
\hline$m_{C A}$ & $-3.10 *$ & -3.08 & $-8.07 * *$ & 0.20 & 0.13 & 0.06 \\
\hline$e_{U S}$ & $-8.30^{* *}$ & $-8.26^{* *}$ & $-8.88^{* *}$ & 0.17 & $\overline{0.15}$ & $\overline{0.03}$ \\
\hline$e_{J A}$ & $-7.51 * *$ & $-7.77^{* *}$ & -7.87 ** & 0.21 & 0.03 & 0.03 \\
\hline$e_{E A}$ & $-6.98 * *$ & $-6.93^{* *}$ & $-7.50 * *$ & 0.12 & 0.07 & 0.02 \\
\hline$e_{U K}$ & $-7.81^{* *}$ & $-7.86^{* *}$ & $-7.96^{* *}$ & 0.05 & 0.04 & 0.03 \\
\hline$e_{C A}$ & $-6.95^{* *}$ & $-6.97 * *$ & $-7.51^{* *}$ & 0.15 & $0.15^{*}$ & 0.04 \\
\hline$\overline{\overline{f_{U S}}}$ & $-9.28^{* *}$ & $-9.36^{* *}$ & $-9.59^{* *}$ & $\overline{0.10}$ & 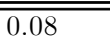 & 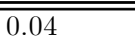 \\
\hline$f_{J A}$ & $-11.49 * *$ & $-11.67^{* *}$ & $-12.54^{* *}$ & 0.25 & 0.08 & 0.05 \\
\hline$f_{E A}$ & $-6.35^{* *}$ & $-6.46^{* *}$ & $-6.55^{* *}$ & 0.08 & 0.05 & 0.05 \\
\hline$f_{U K}$ & $-10.61^{* *}$ & $-10.83^{* *}$ & $-11.26^{* *}$ & 0.18 & 0.04 & 0.04 \\
\hline$f_{C A}$ & $-8.93^{* *}$ & $-8.88^{* *}$ & $-8.96^{* *}$ & 0.06 & 0.03 & 0.03 \\
\hline$o_{U S}$ & $\overline{-7.89^{* *}}$ & $-7.96^{* *}$ & $-8.79^{* *}$ & $\overline{0.32}$ & 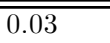 & 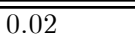 \\
\hline$o_{J A}$ & $-7.48 * *$ & $-7.84^{* *}$ & $-8.41^{* *}$ & 0.30 & 0.04 & 0.03 \\
\hline$o_{E A}$ & $-7.38 * *$ & $-7.96 * *$ & $-8.54^{* *}$ & 0.22 & 0.05 & 0.03 \\
\hline$o_{U K}$ & $-7.96 * *$ & $-7.43^{* *}$ & $-8.74^{* *}$ & 0.23 & 0.04 & 0.03 \\
\hline$o_{C A}$ & $-8.13 * *$ & $-8.14^{* *}$ & $-9.04 * *$ & 0.31 & 0.03 & 0.02 \\
\hline
\end{tabular}

The first (last) three numeric columns report the ADF (KPSS) tests for three specifications of the deterministic trend: a constant $\left(A D F_{m}\right.$ and $\left.K P S S_{m}\right)$, a constant plus a linear trend $\left(\left(A D F_{t}\right.\right.$ and $\left.K P S S_{t}\right)$, and a constant plus a non linear trend (Enders and Lee, 2005) $\left(A D F_{n l t}\right.$ and $\left.K P S S_{n l t}\right)$. For the $A D F$ tests critical values are $-2.89(-3.50),-3.46(-4.06)$, and $-4.35(-4.95)$, for the $5 \%(1 \%)$ significance level. The corresponding values for the KPSS tests are $0.46(0.73), 0.15(0.22)$, and 0.06 (0.08). Critical values for the $K P S S_{n l t}$ test have been tabulated by means of Monte Carlo simulations with 10.000 replications. ${ }^{*}$ and ${ }^{* *}$ denote significance at the $5 \%$ and $1 \%$ level respectively. Definitions of the series are given in the text. 
Table 2

Principal components analysis on separate sub-sets of variables

\begin{tabular}{llllll||llllll} 
& $P C_{1}$ & $P C_{2}$ & $P C_{3}$ & $P C_{4}$ & $P C_{5}$ & & $P C_{1}$ & $P C_{2}$ & $P C_{3}$ & $P C_{4}$ & $P C_{5}$ \\
\hline \hline$g$ (all) & 0.40 & 0.23 & 0.16 & 0.13 & 0.08 & $m_{\text {all }}$ & 0.49 & 0.20 & 0.14 & 0.12 & 0.06 \\
\hline$g_{U S}$ & 0.66 & 0.07 & 0.06 & 0.00 & 0.21 & $m_{U S}$ & 0.28 & 0.40 & 0.25 & 0.07 & 0.00 \\
$g_{J A}$ & 0.04 & 0.64 & 0.24 & 0.08 & 0.00 & $m_{J A}$ & 0.70 & 0.00 & 0.01 & 0.18 & 0.12 \\
$g_{E A}$ & 0.32 & 0.27 & 0.09 & 0.31 & 0.00 & $m_{E A}$ & 0.46 & 0.02 & 0.34 & 0.18 & 0.00 \\
$g_{U K}$ & 0.43 & 0.01 & 0.31 & 0.25 & 0.00 & $m_{U K}$ & 0.75 & 0.01 & 0.00 & 0.07 & 0.16 \\
$g_{C A}$ & 0.56 & 0.16 & 0.10 & 0.00 & 0.18 & $m_{C A}$ & 0.24 & 0.56 & 0.09 & 0.10 & 0.01 \\
\hline \hline$\pi$ (all) & 0.70 & 0.11 & 0.08 & 0.06 & 0.04 & $e_{(a l l)}$ & 0.37 & 0.24 & 0.21 & 0.18 & 0.01 \\
\hline$\pi_{U S}$ & 0.72 & 0.00 & 0.18 & 0.08 & 0.02 & $e_{U S}$ & 0.76 & 0.04 & 0.18 & 0.01 & 0.02 \\
$\pi_{J A}$ & 0.56 & 0.36 & 0.06 & 0.00 & 0.01 & $e_{J A}$ & 0.31 & 0.30 & 0.13 & 0.24 & 0.01 \\
$\pi_{E A}$ & 0.71 & 0.09 & 0.13 & 0.00 & 0.07 & $e_{E A}$ & 0.58 & 0.28 & 0.06 & 0.06 & 0.02 \\
$\pi_{U K}$ & 0.76 & 0.00 & 0.04 & 0.20 & 0.00 & $e_{U K}$ & 0.04 & 0.54 & 0.23 & 0.19 & 0.00 \\
$\pi_{C A}$ & 0.76 & 0.11 & 0.00 & 0.01 & 0.12 & $e_{C A}$ & 0.15 & 0.03 & 0.43 & 0.39 & 0.00 \\
\hline \hline$s_{\text {(all) }}$ & 0.88 & 0.06 & 0.04 & 0.02 & 0.01 & $f($ all $)$ & 0.57 & 0.19 & 0.13 & 0.08 & 0.03 \\
\hline$s_{U S}$ & 0.82 & 0.15 & 0.01 & 0.02 & 0.00 & $f_{U S}$ & 0.82 & 0.02 & 0.07 & 0.00 & 0.09 \\
$s_{J A}$ & 0.88 & 0.09 & 0.04 & 0.02 & 0.02 & $f_{J A}$ & 0.07 & 0.92 & 0.01 & 0.00 & 0.00 \\
$s_{E A}$ & 0.90 & 0.04 & 0.00 & 0.00 & 0.02 & $f_{E A}$ & 0.55 & 0.00 & 0.32 & 0.12 & 0.00 \\
$s_{U K}$ & 0.86 & 0.00 & 0.13 & 0.00 & 0.00 & $f_{U K}$ & 0.69 & 0.00 & 0.07 & 0.23 & 0.01 \\
$s_{C A}$ & 0.93 & 0.02 & 0.00 & 0.04 & 0.01 & $f_{C A}$ & 0.70 & 0.02 & 0.19 & 0.03 & 0.05 \\
\hline \hline$l$ (all) & 0.95 & 0.02 & 0.01 & 0.01 & 0.01 & $o($ all $)$ & 0.95 & 0.02 & 0.02 & 0.01 & 0.00 \\
\hline$l_{U S}$ & 0.94 & 0.05 & 0.00 & 0.00 & 0.01 & $o_{U S}$ & 0.96 & 0.03 & 0.00 & 0.00 & 0.01 \\
$l_{J A}$ & 0.94 & 0.04 & 0.02 & 0.00 & 0.00 & $o_{J A}$ & 0.93 & 0.01 & 0.05 & 0.00 & 0.00 \\
$l_{E A}$ & 0.96 & 0.00 & 0.03 & 0.01 & 0.00 & $o_{E A}$ & 0.96 & 0.02 & 0.01 & 0.02 & 0.00 \\
$l_{U K}$ & 0.96 & 0.01 & 0.00 & 0.03 & 0.00 & $o_{U K}$ & 0.95 & 0.01 & 0.02 & 0.01 & 0.00 \\
$l_{C A}$ & 0.97 & 0.01 & 0.00 & 0.00 & 0.02 & $o_{C A}$ & 0.96 & 0.03 & 0.00 & 0.00 & 0.01 \\
\hline \hline
\end{tabular}

This table reports the results of the principal components $(P C)$ analysis conducted on 8 sub-sets of series, each comprising the same variable for all the 5 regions. For each set the first row shows the fraction of the total variance explained by each $P C_{i}(i=1, \ldots 5)$; the subsequent five rows display the fraction of the variance of the individual series attributable to each $P C_{i}$. The $P C$ analysis is carried out on the standardized variables. 
Table 3

Principal components analysis: inflation, interest rates and money growth as a group

\begin{tabular}{ccccccccccc} 
& $P C_{1}$ & $P C_{2}$ & $P C_{3}$ & $P C_{4}$ & $P C_{5}$ & $P C_{6}$ & $P C_{7}$ & $P C_{8}$ & $P C_{9}$ & $P C_{10}$ \\
\hline \hline$\pi, s, l, m(\mathrm{all})$ & 0.65 & 0.08 & 0.04 & 0.04 & 0.04 & 0.03 & 0.02 & 0.02 & 0.02 & 0.01 \\
\hline$\pi_{U S}$ & 0.45 & 0.11 & 0.18 & 0.04 & 0.06 & 0.01 & 0.01 & 0.00 & 0.06 & 0.06 \\
$\pi_{J A}$ & 0.44 & 0.00 & 0.12 & 0.00 & 0.08 & 0.28 & 0.00 & 0.05 & 0.01 & 0.01 \\
$\pi_{E A}$ & 0.71 & 0.01 & 0.00 & 0.17 & 0.01 & 0.02 & 0.00 & 0.00 & 0.00 & 0.02 \\
$\pi_{U K}$ & 0.63 & 0.09 & 0.06 & 0.00 & 0.02 & 0.00 & 0.01 & 0.09 & 0.03 & 0.05 \\
$\pi_{C A}$ & 0.62 & 0.04 & 0.00 & 0.12 & 0.02 & 0.04 & 0.01 & 0.00 & 0.04 & 0.01 \\
$s_{U S}$ & 0.83 & 0.00 & 0.01 & 0.01 & 0.04 & 0.04 & 0.00 & 0.00 & 0.00 & 0.01 \\
$s_{J A}$ & 0.83 & 0.07 & 0.00 & 0.00 & 0.01 & 0.01 & 0.03 & 0.00 & 0.00 & 0.01 \\
$s_{E A}$ & 0.83 & 0.10 & 0.00 & 0.00 & 0.01 & 0.00 & 0.01 & 0.00 & 0.00 & 0.00 \\
$s_{U K}$ & 0.81 & 0.00 & 0.00 & 0.05 & 0.00 & 0.04 & 0.01 & 0.04 & 0.01 & 0.01 \\
$s_{C A}$ & 0.91 & 0.00 & 0.00 & 0.00 & 0.01 & 0.01 & 0.00 & 0.00 & 0.00 & 0.00 \\
$l_{U S}$ & 0.88 & 0.02 & 0.01 & 0.00 & 0.00 & 0.02 & 0.00 & 0.01 & 0.01 & 0.01 \\
$l_{J A}$ & 0.90 & 0.05 & 0.00 & 0.00 & 0.00 & 0.00 & 0.01 & 0.00 & 0.00 & 0.01 \\
$l_{E A}$ & 0.96 & 0.10 & 0.00 & 0.00 & 0.00 & 0.01 & 0.00 & 0.01 & 0.00 & 0.00 \\
$l_{U K}$ & 0.93 & 0.02 & 0.00 & 0.02 & 0.00 & 0.00 & 0.00 & 0.00 & 0.00 & 0.00 \\
$l_{C A}$ & 0.94 & 0.01 & 0.00 & 0.00 & 0.00 & 0.02 & 0.00 & 0.01 & 0.00 & 0.00 \\
$m_{U S}$ & 0.09 & 0.05 & 0.53 & 0.06 & 0.17 & 0.01 & 0.08 & 0.00 & 0.00 & 0.00 \\
$m_{J A}$ & 0.47 & 0.08 & 0.10 & 0.15 & 0.01 & 0.00 & 0.07 & 0.01 & 0.06 & 0.00 \\
$m_{E A}$ & 0.35 & 0.00 & 0.08 & 0.19 & 0.25 & 0.07 & 0.03 & 0.00 & 0.00 & 0.00 \\
$m_{U K}$ & 0.47 & 0.21 & 0.05 & 0.05 & 0.00 & 0.00 & 0.03 & 0.09 & 0.07 & 0.01 \\
$m_{C A}$ & 0.05 & 0.59 & 0.05 & 0.00 & 0.11 & 0.00 & 0.16 & 0.01 & 0.01 & 0.00 \\
\hline \hline
\end{tabular}

This table reports results for the first ten principal components $(P C)$ extracted from a set of variables including the inflation rates, the short-term and long-term interest rates and the nominal money growth rates for all regions. The first row shows the fraction of the total variance explained by each $P C_{i}(i=1, \ldots 10)$; the subsequent rows display the fraction of the variance of the individual series attributable to each $P C_{i}$. The $P C$ analysis is carried out on the standardized variables. 
Table 4

Principal components analysis by country

\begin{tabular}{|c|c|c|c|c|c|c|c|c|}
\hline & $P C_{1}$ & $P C_{2}$ & $P C_{3}$ & $P C_{4}$ & $\mathrm{PC}_{5}$ & $P C_{6}$ & $P C_{7}$ & $P C_{8}$ \\
\hline$U S$ (all) & 0.34 & 0.19 & 0.13 & 0.12 & 0.10 & 0.08 & 0.04 & 0.00 \\
\hline$g_{U S}$ & 0.04 & 0.03 & 0.33 & 0.60 & 0.01 & 0.00 & 0.00 & 0.00 \\
\hline$\pi_{U S}$ & 0.55 & 0.21 & 0.00 & 0.00 & 0.05 & 0.00 & 0.19 & 0.00 \\
\hline$s_{U S}$ & 0.92 & 0.01 & 0.00 & 0.01 & 0.01 & 0.01 & 0.01 & 0.03 \\
\hline$l_{U S}$ & 0.83 & 0.01 & 0.00 & 0.01 & 0.01 & 0.06 & 0.06 & 0.02 \\
\hline$m_{U S}$ & 0.18 & 0.20 & 0.19 & 0.13 & 0.05 & 0.25 & 0.00 & 0.00 \\
\hline$e_{U S}$ & 0.14 & 0.01 & 0.47 & 0.18 & 0.08 & 0.13 & 0.00 & 0.00 \\
\hline$f_{U S}$ & 0.03 & 0.35 & 0.06 & 0.00 & 0.54 & 0.02 & 0.00 & 0.00 \\
\hline$o_{U S}$ & 0.00 & 0.71 & 0.01 & 0.00 & 0.09 & 0.13 & 0.07 & 0.00 \\
\hline$J A$ (all) & 0.38 & 0.19 & 0.13 & 0.11 & 0.08 & 0.06 & 0.05 & 0.00 \\
\hline$g_{J A}$ & 0.10 & 0.30 & 0.20 & 0.26 & 0.03 & 0.07 & 0.04 & 0.00 \\
\hline$\pi_{J A}$ & 0.52 & 0.02 & 0.14 & 0.08 & 0.00 & 0.04 & 0.20 & 0.00 \\
\hline$s_{J A}$ & 0.88 & 0.01 & 0.01 & 0.00 & 0.00 & 0.02 & 0.07 & 0.01 \\
\hline$l_{J A}$ & 0.90 & 0.00 & 0.03 & 0.00 & 0.01 & 0.00 & 0.05 & 0.01 \\
\hline$m_{J A}$ & 0.50 & 0.12 & 0.04 & 0.00 & 0.07 & 0.26 & 0.01 & 0.00 \\
\hline$e_{J A}$ & 0.05 & 0.36 & 0.28 & 0.03 & 0.26 & 0.02 & 0.00 & 0.00 \\
\hline$f_{J A}$ & 0.01 & 0.29 & 0.16 & 0.49 & 0.01 & 0.03 & 0.01 & 0.00 \\
\hline$o_{J A}$ & 0.05 & 0.42 & 0.20 & 0.02 & 0.28 & 0.03 & 0.00 & 0.00 \\
\hline$E A$ (all) & 0.40 & 0.18 & 0.15 & 0.11 & 0.07 & 0.06 & 0.03 & 0.00 \\
\hline$g_{E A}$ & 0.05 & 0.04 & 0.22 & 0.68 & 0.01 & 0.00 & 0.00 & 0.00 \\
\hline$\pi_{E A}$ & 0.85 & 0.01 & 0.02 & 0.00 & 0.00 & 0.00 & 0.12 & 0.00 \\
\hline$s_{E A}$ & 0.86 & 0.00 & 0.02 & 0.01 & 0.07 & 0.00 & 0.02 & 0.02 \\
\hline$l_{E A}$ & 0.86 & 0.00 & 0.03 & 0.01 & 0.08 & 0.00 & 0.01 & 0.01 \\
\hline$m_{E A}$ & 0.53 & 0.02 & 0.00 & 0.00 & 0.43 & 0.00 & 0.02 & 0.00 \\
\hline$e_{E A}$ & 0.04 & 0.75 & 0.00 & 0.01 & 0.00 & 0.20 & 0.00 & 0.00 \\
\hline$f_{E A}$ & 0.01 & 0.34 & 0.38 & 0.15 & 0.00 & 0.12 & 0.00 & 0.00 \\
\hline$o_{E A}$ & 0.00 & 0.28 & 0.53 & 0.06 & 0.00 & 0.13 & 0.00 & 0.00 \\
\hline$U K$ (all) & 0.41 & 0.16 & 0.13 & 0.11 & 0.09 & 0.05 & 0.03 & 0.02 \\
\hline$g_{U K}$ & 0.19 & 0.31 & 0.01 & 0.17 & 0.27 & 0.05 & 0.00 & 0.00 \\
\hline$\pi_{U K}$ & 0.78 & 0.01 & 0.01 & 0.01 & 0.01 & 0.01 & 0.17 & 0.00 \\
\hline$s_{U K}$ & 0.89 & 0.01 & 0.00 & 0.00 & 0.00 & 0.02 & 0.02 & 0.06 \\
\hline$l_{U K}$ & 0.82 & 0.03 & 0.01 & 0.00 & 0.00 & 0.05 & 0.06 & 0.03 \\
\hline$m_{U K}$ & 0.60 & 0.04 & 0.01 & 0.02 & 0.06 & 0.27 & 0.00 & 0.00 \\
\hline$e_{U K}$ & 0.02 & 0.33 & 0.36 & 0.11 & 0.17 & 0.01 & 0.00 & 0.00 \\
\hline$f_{U K}$ & 0.01 & 0.38 & 0.01 & 0.58 & 0.01 & 0.00 & 0.01 & 0.00 \\
\hline$o_{U K}$ & 0.01 & 0.18 & 0.65 & 0.00 & 0.16 & 0.00 & 0.00 & 0.00 \\
\hline$C A$ (all) & 0.36 & 0.16 & 0.15 & 0.12 & 0.09 & 0.07 & 0.04 & 0.01 \\
\hline$g_{C A}$ & 0.19 & 0.00 & 0.14 & 0.49 & 0.00 & 0.18 & 0.00 & 0.00 \\
\hline$\pi_{C A}$ & 0.75 & 0.00 & 0.01 & 0.01 & 0.01 & 0.00 & 0.22 & 0.00 \\
\hline$s_{C A}$ & 0.89 & 0.00 & 0.00 & 0.04 & 0.00 & 0.00 & 0.05 & 0.02 \\
\hline$l_{C A}$ & 0.84 & 0.01 & 0.00 & 0.10 & 0.00 & 0.00 & 0.03 & 0.02 \\
\hline$m_{C A}$ & 0.13 & 0.18 & 0.25 & 0.10 & 0.31 & 0.03 & 0.00 & 0.00 \\
\hline$e_{C A}$ & 0.04 & 0.58 & 0.01 & 0.05 & 0.25 & 0.07 & 0.00 & 0.00 \\
\hline$f_{C A}$ & 0.08 & 0.49 & 0.02 & 0.16 & 0.04 & 0.21 & 0.00 & 0.00 \\
\hline$o_{C A}$ & 0.02 & 0.00 & 0.74 & 0.01 & 0.12 & 0.11 & 0.00 & 0.00 \\
\hline
\end{tabular}

This table reports the results of the $P C$ analysis conducted separately on all variables for each country/region. For each set the first row shows the fraction of the total variance explained by each $P C_{i}(i=1, \ldots 8)$; the subsequent eight rows display the fraction of the variance of the individual series attributable to each $P C_{i}$. The $P C$ analysis is carried out on the standardized variables. 
Table 5

Variance decomposition based on the four-factor $F-V A R$

\begin{tabular}{|c|c|c|c|c|c|c|c|c|}
\hline \multirow{2}{*}{\multicolumn{2}{|c|}{$\begin{array}{l}\text { Horizon } \\
\text { (quarters) }\end{array}$}} & \multicolumn{5}{|c|}{ Global shocks } & \multicolumn{2}{|c|}{ Idiosyncratic shock } \\
\hline & & output & inflation & stock mkt. & oil price & All & domestic & All \\
\hline \multirow[t]{2}{*}{$g_{U S}$} & $\overline{1}$ & 24.9 & 23.3 & $\overline{1.4}$ & 0.0 & 49.6 & 50.4 & 50.4 \\
\hline & 20 & 25.1 & 33.9 & 3.7 & 0.0 & 62.9 & 16.7 & 37.1 \\
\hline \multirow[t]{2}{*}{$\pi_{U S}$} & 1 & 0.5 & 96.9 & 0.1 & 0.2 & 97.7 & 2.3 & 2.3 \\
\hline & 20 & 1.8 & 95.2 & 0.5 & 0.9 & 98.3 & 1.2 & 1.7 \\
\hline \multirow[t]{2}{*}{$s_{U S}$} & 1 & 0.0 & 98.7 & 0.0 & 0.1 & 98.8 & 1.0 & 1.2 \\
\hline & 20 & 0.3 & 97.1 & 0.1 & 0.3 & 97.8 & 1.3 & 2.2 \\
\hline \multirow[t]{2}{*}{$l_{U S}$} & 1 & 0.0 & 98.4 & 0.0 & 0.1 & 98.5 & 1.2 & 1.5 \\
\hline & 20 & 0.4 & 95.3 & 0.1 & 0.4 & 96.3 & 2.0 & 3.7 \\
\hline \multirow[t]{2}{*}{$m_{U S}$} & 1 & 0.1 & 90.9 & 0.0 & 0.0 & 91.0 & 5.0 & 9.0 \\
\hline & 20 & 1.0 & 90.2 & 0.1 & 0.6 & 91.9 & 2.9 & 8.1 \\
\hline \multirow{2}{*}{$e_{U S}$} & 1 & 8.4 & 2.8 & 0.1 & 0.0 & 11.2 & 49.0 & 88.8 \\
\hline & 20 & 1.3 & 15.9 & 0.7 & 2.9 & 20.7 & 40.0 & 79.3 \\
\hline \multirow{2}{*}{$f_{U S}$} & 1 & 25.0 & 45.4 & 0.6 & 1.6 & 72.6 & 14.4 & 27.4 \\
\hline & 20 & 32.4 & 45.2 & 0.2 & 2.4 & 80.3 & 5.5 & 19.7 \\
\hline \multirow[t]{2}{*}{$g_{J A}$} & 1 & 13.8 & 80.4 & 0.5 & 0.1 & 94.9 & 5.1 & 5.1 \\
\hline & 20 & 16.3 & 70.7 & 1.5 & 0.3 & 88.8 & 3.0 & 11.2 \\
\hline \multirow[t]{2}{*}{$\pi_{J A}$} & 1 & 1.5 & 89.3 & 0.0 & 0.0 & 90.9 & 7.1 & 9.1 \\
\hline & 20 & 0.2 & 91.1 & 0.1 & 0.8 & 92.2 & 3.5 & 7.8 \\
\hline \multirow[t]{2}{*}{$s_{J A}$} & 1 & 0.0 & 98.4 & 0.0 & 0.1 & 98.5 & 0.6 & 1.5 \\
\hline & 20 & 0.2 & 93.9 & 0.0 & 0.4 & 94.4 & 1.5 & 5.6 \\
\hline \multirow[t]{2}{*}{$l_{J A}$} & 1 & 0.0 & 98.5 & 0.0 & 0.1 & 98.6 & 0.5 & 1.4 \\
\hline & 20 & 0.2 & 96.5 & 0.0 & 0.3 & 97.0 & 1.1 & 3.0 \\
\hline \multirow[t]{2}{*}{$m_{J A}$} & 1 & 0.3 & 95.1 & 0.0 & 0.1 & 95.5 & 2.6 & 4.5 \\
\hline & 20 & 1.9 & 82.5 & 0.3 & 0.2 & 84.9 & 5.0 & 10.1 \\
\hline \multirow[t]{2}{*}{$e_{J A}$} & 1 & 6.3 & 0.4 & 0.4 & 0.0 & 7.1 & 26.3 & 92.9 \\
\hline & 20 & 6.3 & 1.7 & 0.5 & 0.0 & 8.5 & 26.9 & 91.5 \\
\hline \multirow{2}{*}{$f_{J A}$} & 1 & 0.7 & 30.7 & 0.5 & 0.0 & 31.9 & 31.3 & 68.1 \\
\hline & 20 & 1.3 & 19.8 & 0.7 & 0.8 & 22.5 & 28.8 & 77.5 \\
\hline \multirow[t]{2}{*}{$g_{E A}$} & 1 & 8.9 & 57.2 & 0.1 & 0.1 & 66.2 & 28.0 & 33.8 \\
\hline & 20 & 16.9 & 31.4 & 1.7 & 0.4 & 50.4 & 24.6 & 49.6 \\
\hline \multirow[t]{2}{*}{$\pi_{E A}$} & 1 & 2.4 & 11.5 & 1.1 & 0.1 & 15.0 & 76.9 & 85.0 \\
\hline & 20 & 4.7 & 67.6 & 1.7 & 4.9 & 78.9 & 4.7 & 21.1 \\
\hline \multirow[t]{2}{*}{$s_{E A}$} & 1 & 0.0 & 98.7 & 0.0 & 0.1 & 98.8 & 0.4 & 1.2 \\
\hline & 20 & 0.2 & 96.1 & 0.1 & 0.4 & 96.7 & 0.8 & 3.3 \\
\hline \multirow[t]{2}{*}{$l_{E A}$} & 1 & 0.0 & 98.6 & 0.0 & 0.1 & 98.7 & 0.3 & 1.3 \\
\hline & 20 & 0.3 & 96.0 & 0.1 & 0.5 & 96.9 & 0.6 & 3.1 \\
\hline \multirow[t]{2}{*}{$m_{E A}$} & 1 & 0.0 & 87.8 & 0.0 & 0.0 & 87.8 & 7.1 & 12.2 \\
\hline & 20 & 0.5 & 53.3 & 0.0 & 1.2 & 55.0 & 14.0 & 45.0 \\
\hline \multirow[t]{2}{*}{$e_{E A}$} & 1 & 1.0 & 56.6 & 0.1 & 0.0 & 57.6 & 15.5 & 42.4 \\
\hline & 20 & 0.7 & 6.2 & 2.4 & 2.2 & 11.5 & 27.0 & 88.5 \\
\hline$f_{E A}$ & 1 & 23.7 & 28.0 & 0.2 & 1.0 & 52.8 & 25.0 & 47.2 \\
\hline & 20 & 23.4 & 31.5 & 0.7 & 1.9 & 57.4 & 17.3 & 42.6 \\
\hline
\end{tabular}

(continued) 
(Table 5 continued)

\begin{tabular}{|c|c|c|c|c|c|c|c|c|}
\hline & \multirow{2}{*}{$\begin{array}{l}\text { Horizon } \\
\text { (quarters) }\end{array}$} & \multicolumn{5}{|c|}{ Global shocks } & \multicolumn{2}{|c|}{ Idiosyncratic shocks } \\
\hline & & output & inflation & stock mkt. & oil price & All & domestic & All \\
\hline \multirow[t]{2}{*}{$g_{U K}$} & 1 & 8.0 & 19.2 & 0.2 & 0.6 & 27.9 & 56.6 & 72.1 \\
\hline & 20 & 3.8 & 32.2 & 0.1 & 3.2 & 39.4 & 24.6 & 60.6 \\
\hline \multirow[t]{2}{*}{$\pi_{U K}$} & 1 & 0.0 & 97.8 & 0.0 & 0.1 & 97.9 & 1.5 & 2.1 \\
\hline & 20 & 0.4 & 95.9 & 0.1 & 0.5 & 96.9 & 1.4 & 3.1 \\
\hline \multirow[t]{2}{*}{$s_{U K}$} & 1 & 0.0 & 97.9 & 0.0 & 0.1 & 99.1 & 0.4 & 0.9 \\
\hline & 20 & 0.1 & 99.0 & 0.0 & 0.2 & 98.2 & 0.6 & 1.8 \\
\hline \multirow{2}{*}{$l_{U K}$} & 1 & 0.0 & 99.0 & 0.0 & 0.1 & 99.0 & 0.3 & 1.0 \\
\hline & 20 & 0.2 & 98.1 & 0.0 & 0.2 & 99.6 & 0.4 & 1.4 \\
\hline \multirow[t]{2}{*}{$m_{U K}$} & 1 & 0.1 & 97.8 & 0.0 & 0.0 & 97.9 & 1.4 & 2.1 \\
\hline & 20 & 0.7 & 91.4 & 0.1 & 0.2 & 92.3 & 1.9 & 7.7 \\
\hline \multirow[t]{2}{*}{$e_{U K}$} & 1 & 0.0 & 0.1 & 0.0 & 0.2 & 0.3 & 43.0 & 99.7 \\
\hline & 20 & 1.1 & 2.1 & 0.2 & 0.2 & 3.6 & 36.2 & 96.4 \\
\hline \multirow[t]{2}{*}{$f_{U K}$} & 1 & 6.0 & 70.0 & 1.2 & 1.0 & 78.2 & 9.4 & 21.8 \\
\hline & 20 & 14.5 & 68.4 & 1.5 & 2.7 & 87.1 & 4.9 & 12.9 \\
\hline \multirow[t]{2}{*}{$g_{C A}$} & 1 & 24.0 & 15.7 & 1.4 & 0.0 & 41.2 & 41.7 & 58.8 \\
\hline & 20 & 25.3 & 27.1 & 4.0 & 0.4 & 56.8 & 22.7 & 43.2 \\
\hline \multirow[t]{2}{*}{$\pi_{C A}$} & 1 & 0.1 & 85.6 & 0.0 & 0.1 & 85.8 & 11.2 & 14.2 \\
\hline & 20 & 2.0 & 91.4 & 0.5 & 1.3 & 95.3 & 2.3 & 4.7 \\
\hline \multirow[t]{2}{*}{$s_{C A}$} & 1 & 0.0 & 98.6 & 0.0 & 0.1 & 98.7 & 0.6 & 1.3 \\
\hline & 20 & 0.6 & 96.3 & 0.2 & 0.5 & 97.5 & 0.8 & 2.5 \\
\hline \multirow[t]{2}{*}{$l_{C A}$} & 1 & 0.0 & 98.8 & 0.0 & 0.1 & 98.9 & 0.1 & 1.1 \\
\hline & 20 & 0.5 & 96.6 & 0.1 & 0.5 & 97.7 & 0.4 & 2.3 \\
\hline \multirow[t]{2}{*}{$m_{C A}$} & 1 & 0.3 & 91.5 & 0.1 & 0.0 & 91.9 & 4.7 & 8.1 \\
\hline & 20 & 0.4 & 70.0 & 0.1 & 0.1 & 70.6 & 6.9 & 29.4 \\
\hline \multirow[t]{2}{*}{$e_{C A}$} & 1 & 5.1 & 3.2 & 0.0 & 0.2 & 8.5 & 46.3 & 91.5 \\
\hline & 20 & 0.7 & 0.7 & 0.0 & 0.3 & 1.7 & 35.0 & 98.3 \\
\hline \multirow[t]{2}{*}{$f_{C A}$} & 1 & 22.1 & 0.0 & 0.8 & 1.5 & 24.4 & 25.2 & 75.6 \\
\hline & 20 & 28.7 & 3.9 & 0.5 & 2.9 & 36.0 & 7.7 & 64.0 \\
\hline
\end{tabular}

This table reports for each endogenous variable the median forecast error variance decomposition at the one-quarter and five-year horizons obtained from the structural VMA representation of the four-factor $F-V A R$ model in (5) by Monte Carlo simulation as suggested in Granger and Jean (2004). For each variable the table shows the percentage of forecast error variance attributable to each global factor shock ("output", "inflation", "stock market" and "oil price") together with their sum ("All", in bold); the last two columns report the percentage of the forecast error variance attributable to the own-country idiosyncratic shocks ("domestic") and the proportion due to all (domestic and foreign) idiosyncratic disturbances ("All", in bold). 
Figure 1

Groups of series with first principal components
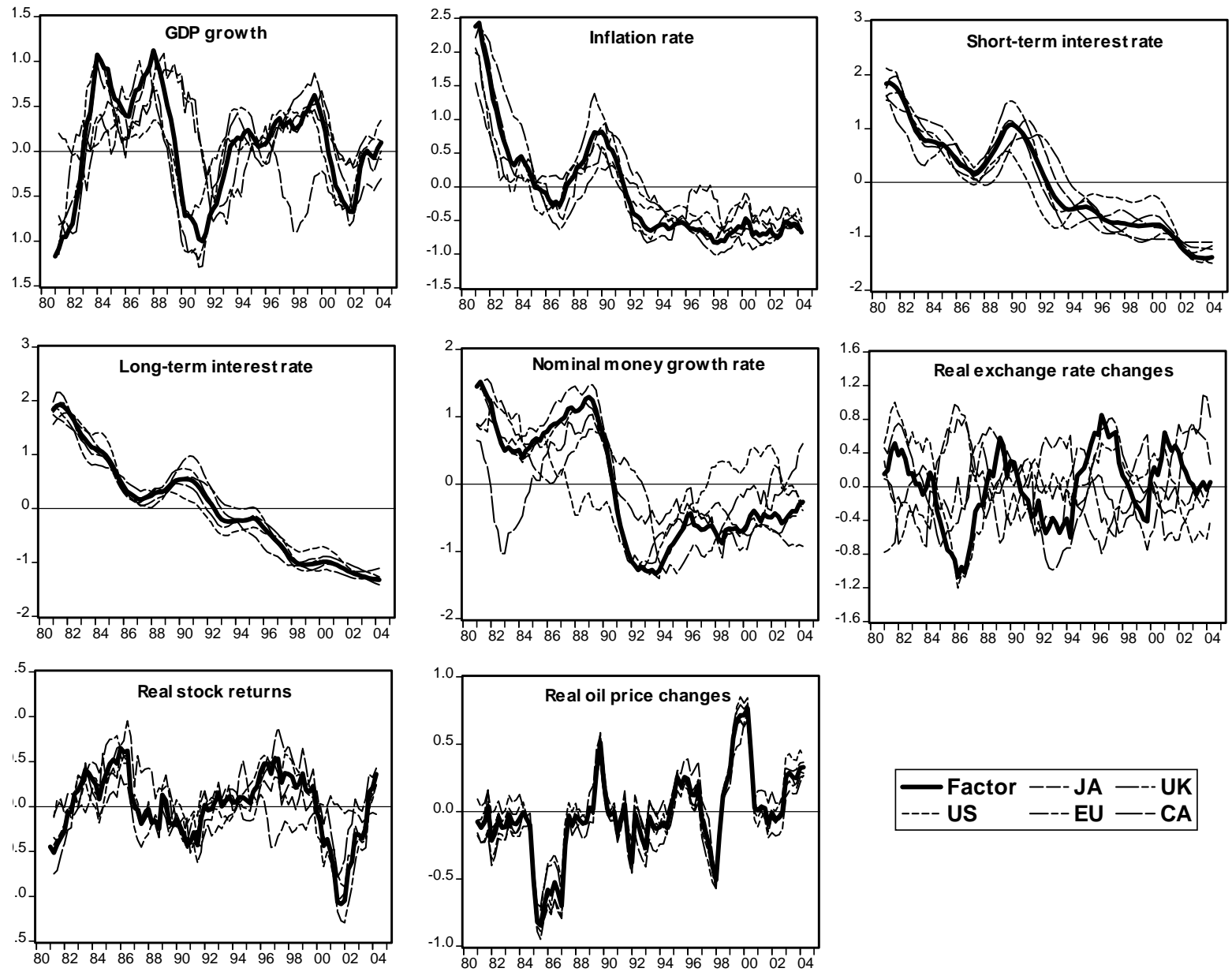

Each panel displays, for each variable in turn, the series for the five countries /regions (dotted lines) from which the first principal component (thick solid line) is extracted. All series are shown as nine-quarter centered moving averages. The sample period is: 1980(1)-2005(2). 


\section{Figure 2}

Global "inflation factor" and inflation rates, interest rates and money growth rates
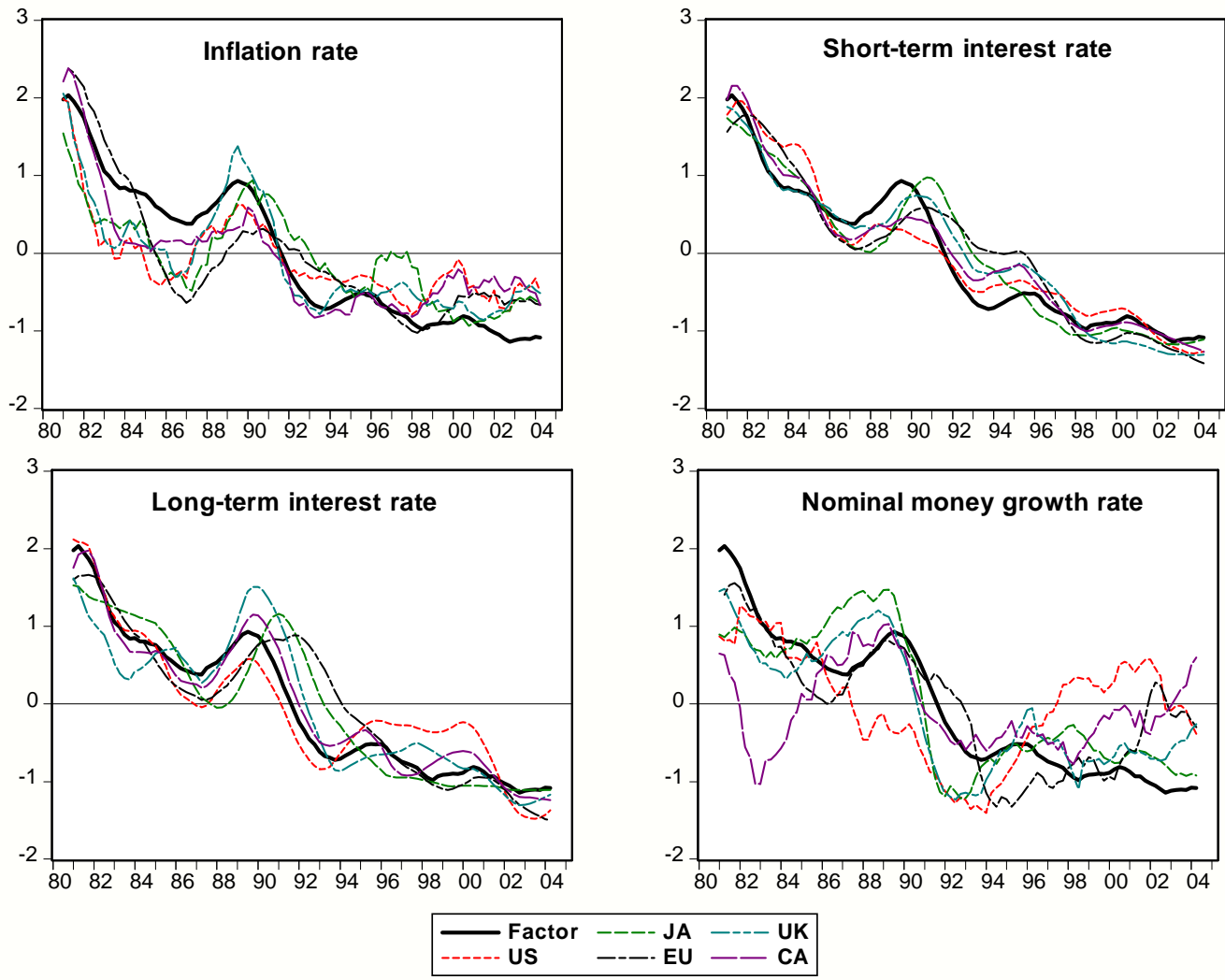

In all panels the thick solid line shows the first principal component extracted from the set of the inflation rates, short-term and long-term interest rates, and nominal money growth rates. The dotted lines show the original $\pi, s, l$ and $m$ series for the five countries/regions. All series are shown as nine-quarter centered moving averages. The sample period is: 1980(1)-2005(2). 


\section{Figure 3}

Impulse response functions to common factor shocks: United States
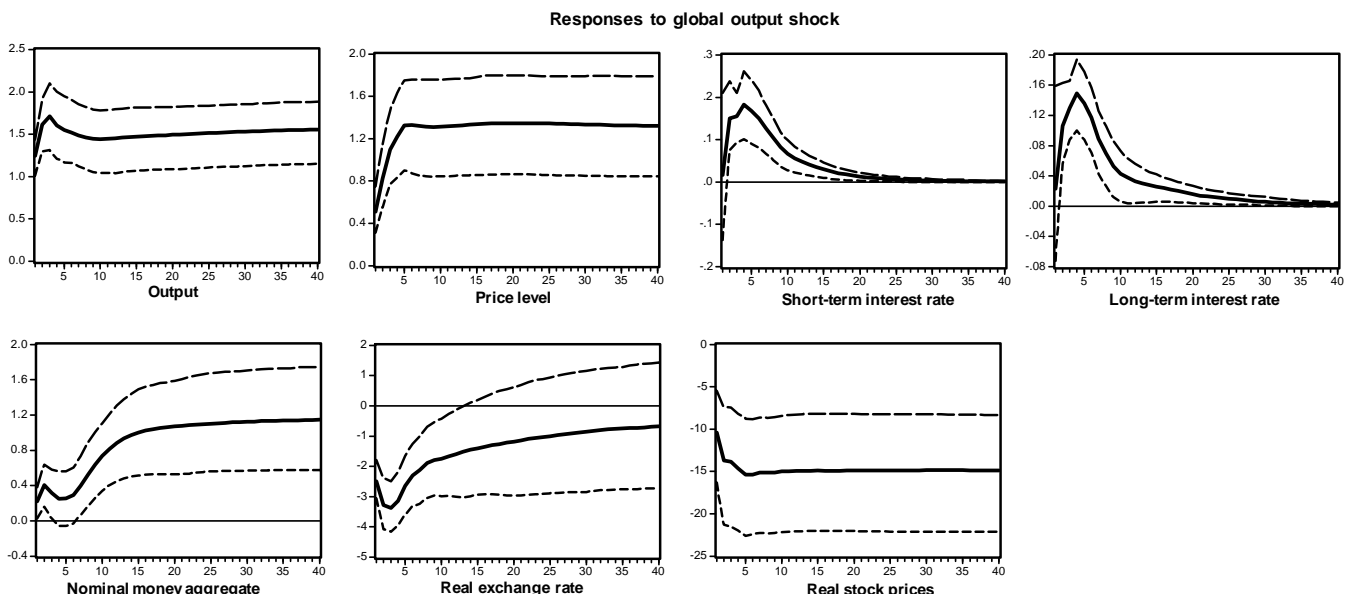

Responses to global inflation shock
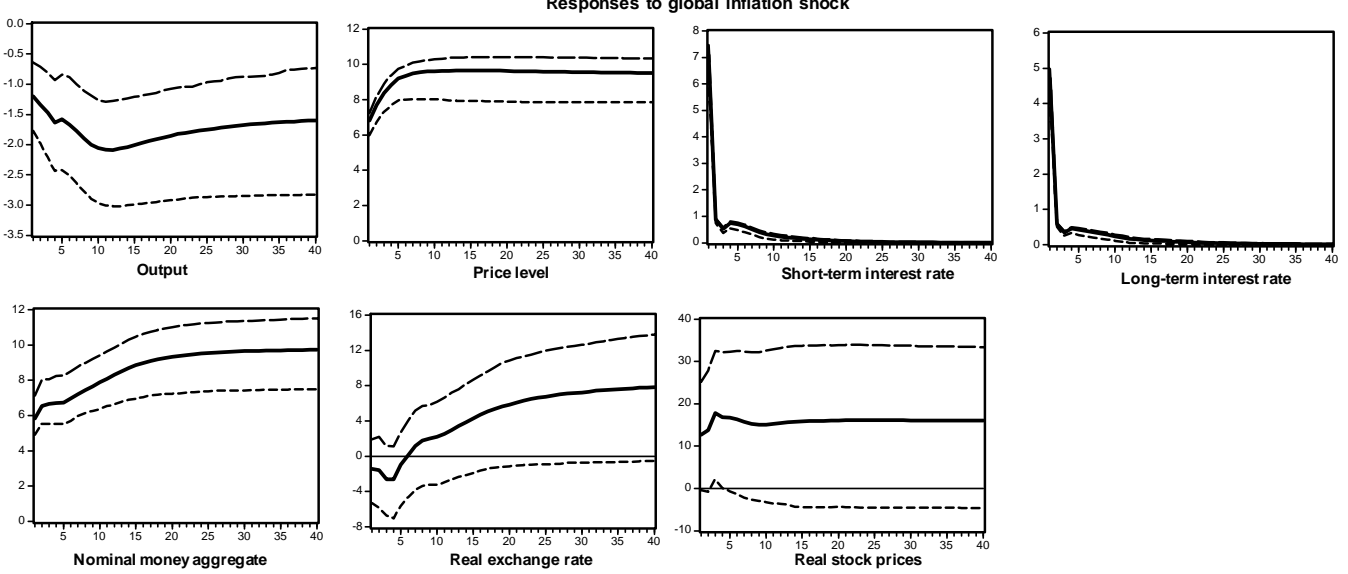

Long-term interest rate

The figure displays the median impulse responses of the level of output, the price level, the short-term interest rate, the long-term interest rate, the nominal money aggregate, the real effective exchange rate and the real stock price index to a onestandard deviation shock to the global "output growth" factor (plots in the first two rows) and to the global "inflation" factor (plots in the last two rows). A 95\% confidence interval, obtained by Monte Carlo simulation, is shown in each plot. The responses are displayed over a ten-year horizon. 


\section{Figure 4}

Impulse response functions to common factor shocks: Japan

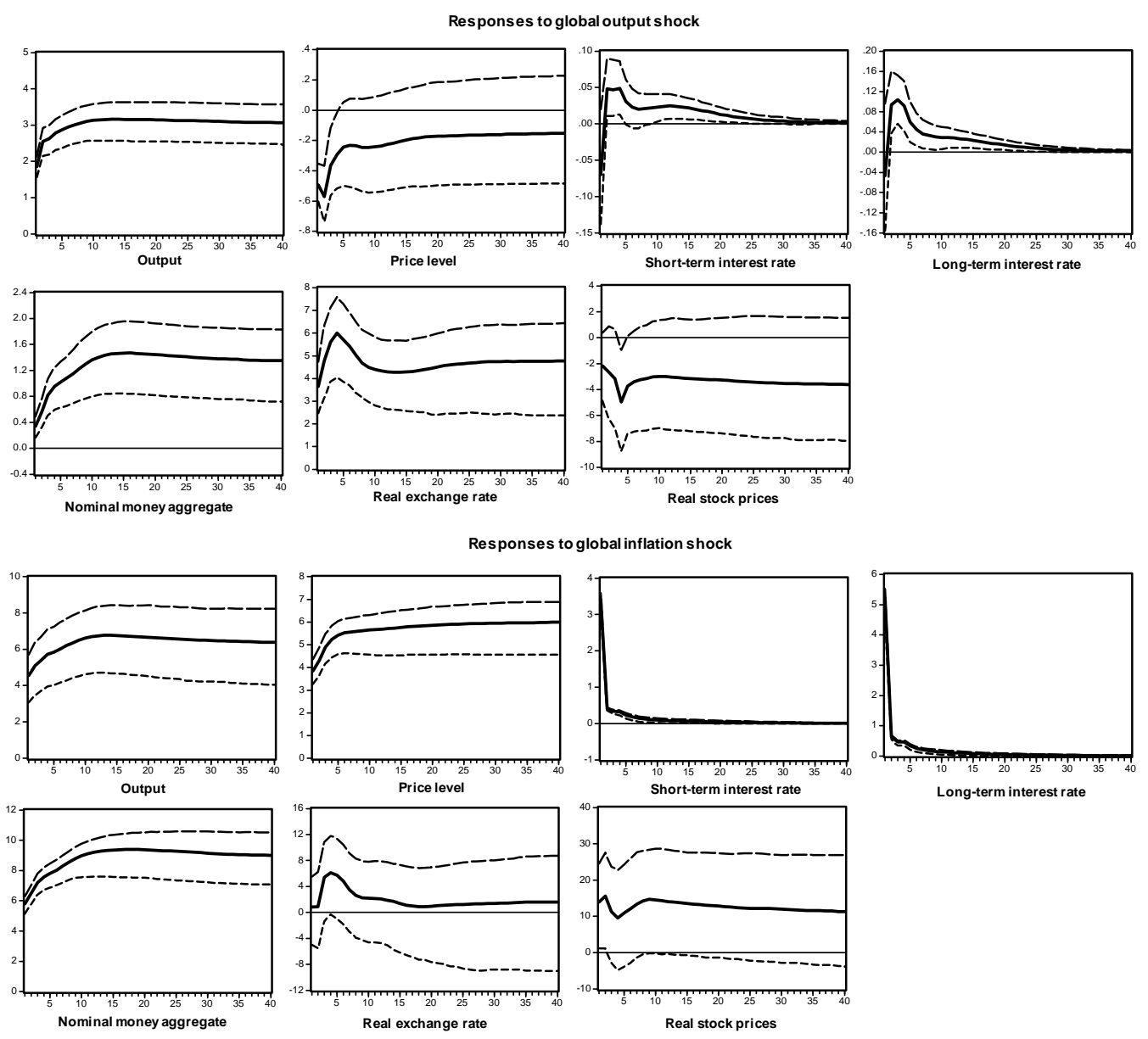

The figure displays the median impulse responses of the level of output, the price level, the short-term interest rate, the long-term interest rate, the nominal money aggregate, the real effective exchange rate and the real stock price index to a onestandard deviation shock to the global "output growth" factor (plots in the first two rows) and to the global "inflation" factor (plots in the last two rows). A 95\% confidence interval, obtained by Monte Carlo simulation, is shown in each plot. The responses are displayed over a ten-year horizon. 


\section{Figure 5}

Impulse response functions to common factor shocks: Euro Area

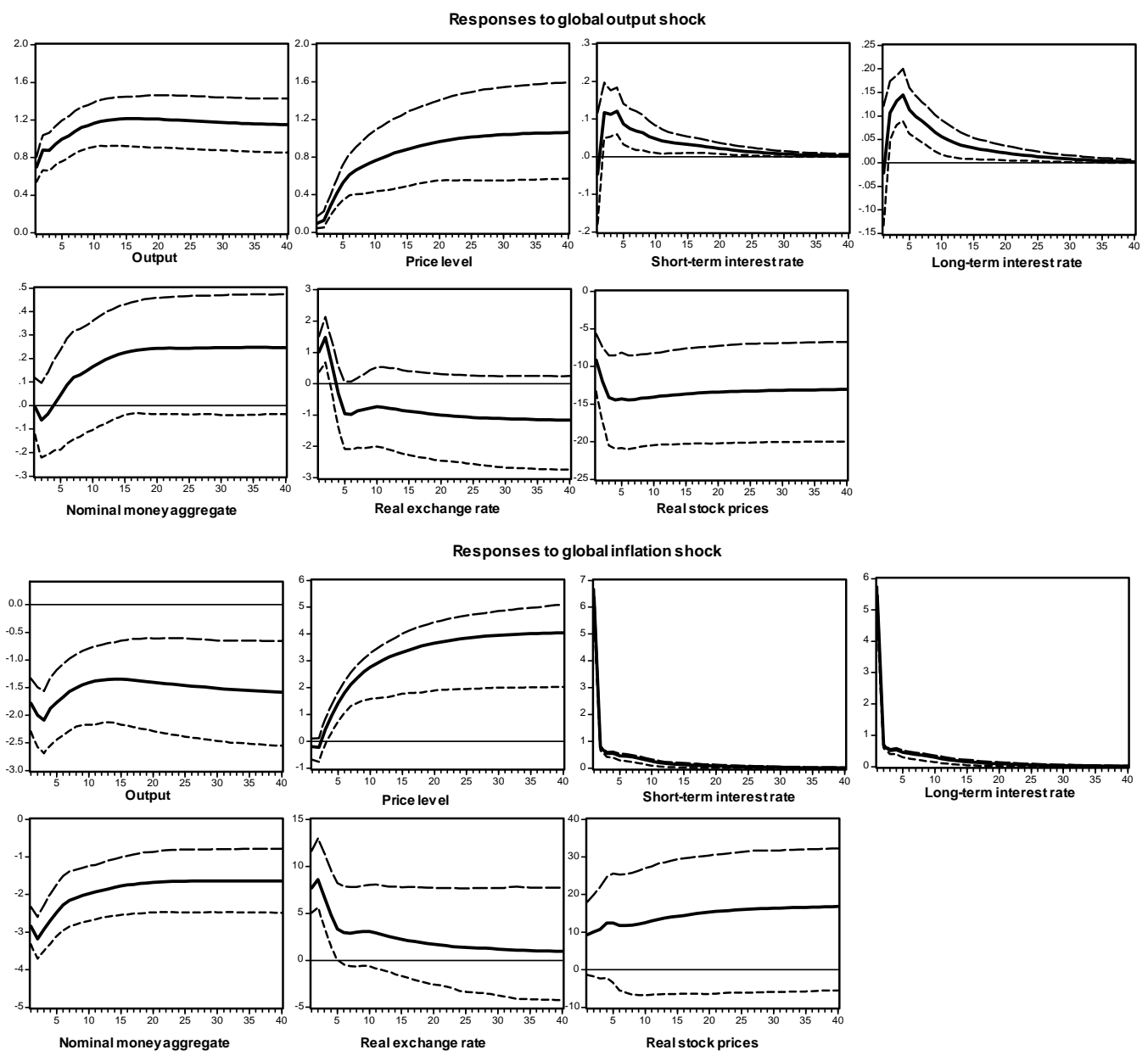

The figure displays the median impulse responses of the level of output, the price level, the short-term interest rate, the long-term interest rate, the nominal money aggregate, the real effective exchange rate and the real stock price index to a onestandard deviation shock to the global "output growth" factor (plots in the first two rows) and to the global "inflation" factor (plots in the last two rows). A 95\% confidence interval, obtained by Monte Carlo simulation, is shown in each plot. The responses are displayed over a ten-year horizon. 


\section{Figure 6}

Impulse response functions to common factor shocks: United Kingdom

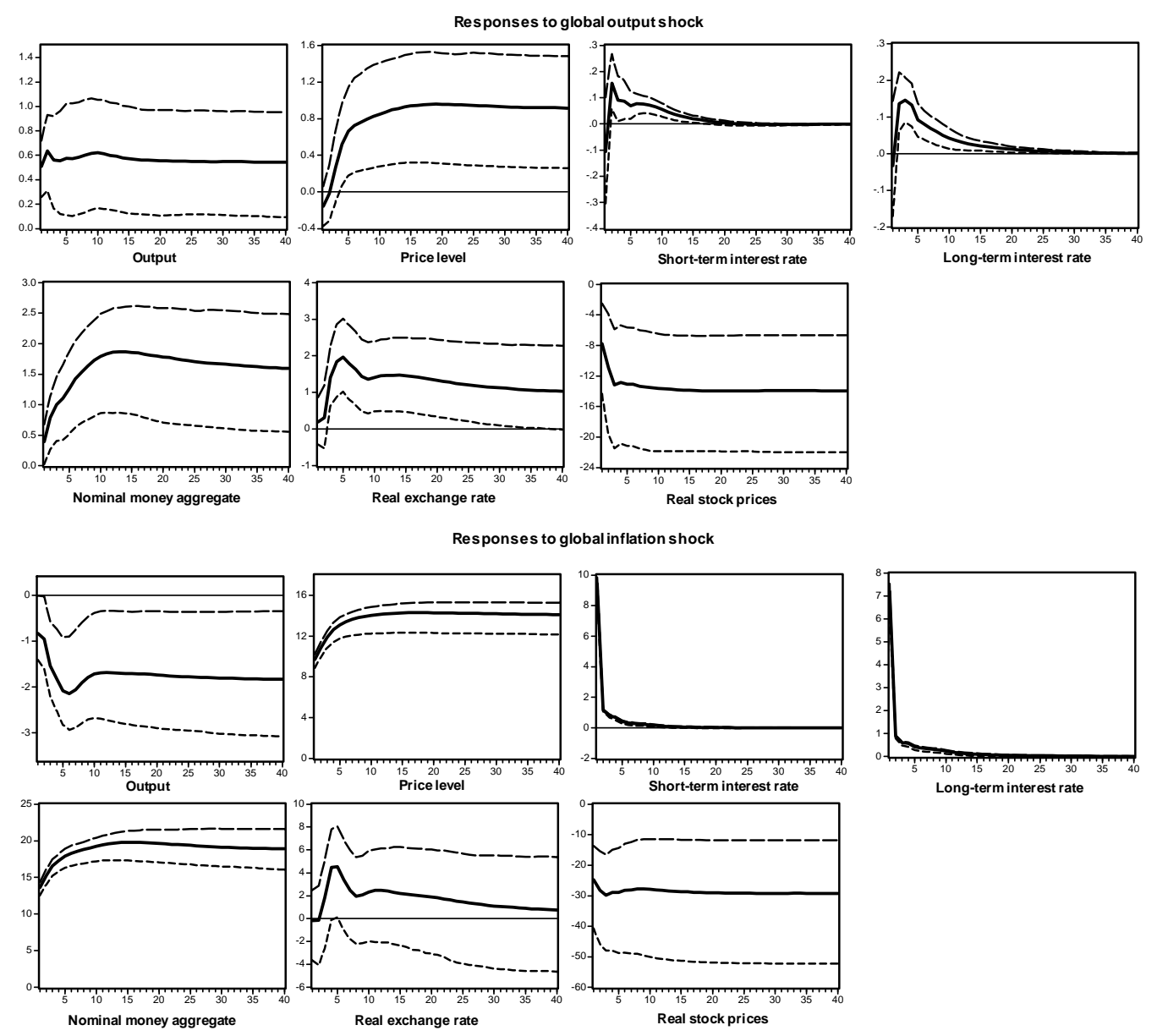

The figure displays the median impulse responses of the level of output, the price level, the short-term interest rate, the long-term interest rate, the nominal money aggregate, the real effective exchange rate and the real stock price index to a onestandard deviation shock to the global "output growth" factor (plots in the first two rows) and to the global "inflation" factor (plots in the last two rows). A 95\% confidence interval, obtained by Monte Carlo simulation, is shown in each plot. The responses are displayed over a ten-year horizon. 


\section{Figure 7}

Impulse response functions to common factor shocks: Canada

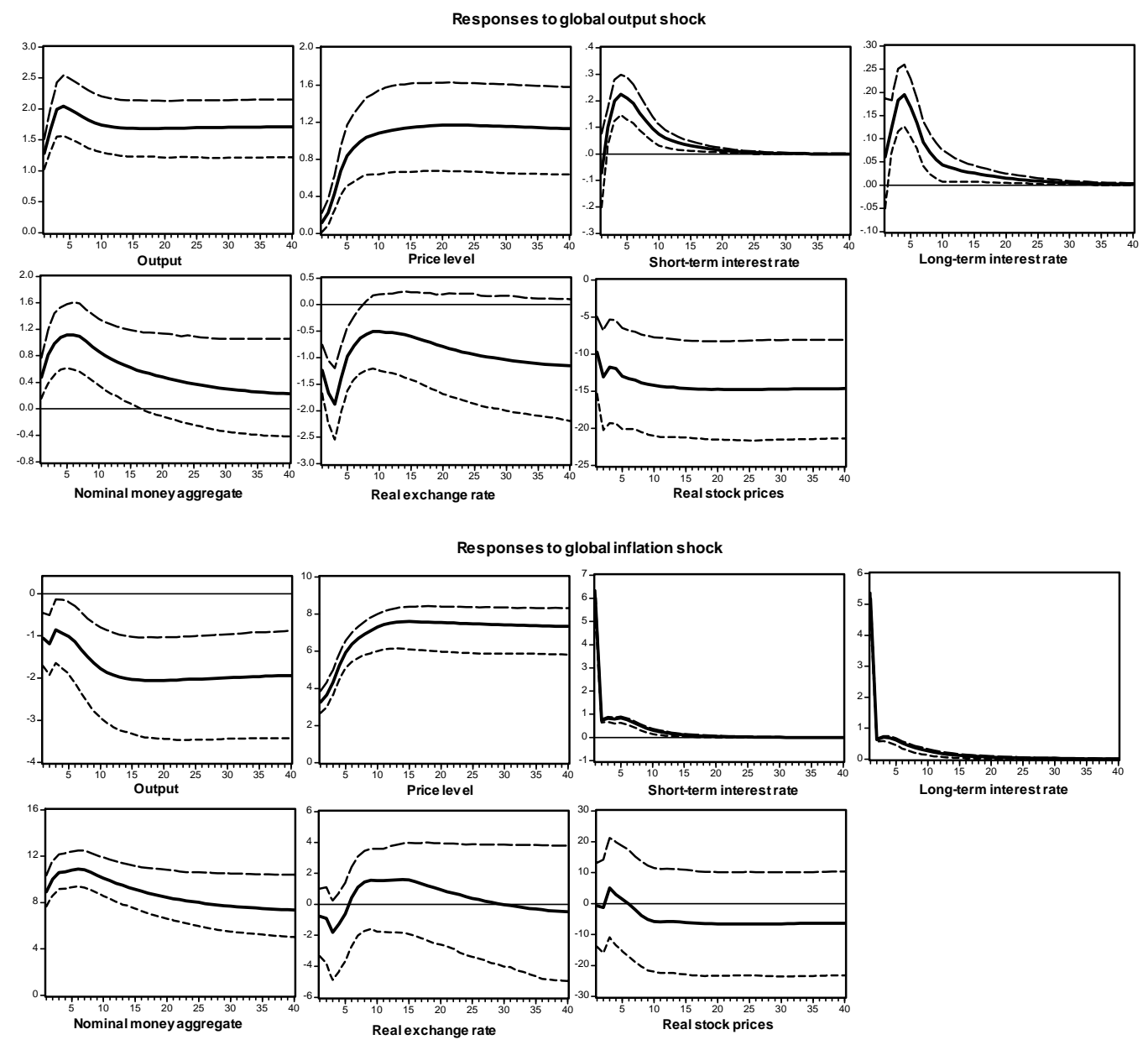

The figure displays the median impulse responses of the level of output, the price level, the short-term interest rate, the long-term interest rate, the nominal money aggregate, the real effective exchange rate and the real stock price index to a onestandard deviation shock to the global "output growth" factor (plots in the first two rows) and to the global "inflation" factor (plots in the last two rows). A 95\% confidence interval, obtained by Monte Carlo simulation, is shown in each plot. The responses are displayed over a ten-year horizon. 